Old Dominion University

ODU Digital Commons

Summer 2016

\title{
Examining Attitudes, Norms, and Control Toward Safety Behaviors as Mediators in the Leadership-Safety Motivation Relationship
}

Gargi Sawhney

Old Dominion University, gargisawhney85@gmail.com

Follow this and additional works at: https://digitalcommons.odu.edu/psychology_etds

Part of the Industrial and Organizational Psychology Commons

\section{Recommended Citation}

Sawhney, Gargi. "Examining Attitudes, Norms, and Control Toward Safety Behaviors as Mediators in the Leadership-Safety Motivation Relationship" (2016). Doctor of Philosophy (PhD), Dissertation, Psychology, Old Dominion University, DOI: 10.25777/x3wg-7d76

https://digitalcommons.odu.edu/psychology_etds/35

This Dissertation is brought to you for free and open access by the Psychology at ODU Digital Commons. It has been accepted for inclusion in Psychology Theses \& Dissertations by an authorized administrator of ODU Digital Commons. For more information, please contact digitalcommons@odu.edu. 


\title{
EXAMINING ATTITUDES, NORMS, AND CONTROL TOWARD SAFETY \\ BEHAVIORS AS MEDIATORS IN THE LEADERSHIP-SAFETY MOTIVATION RELATIONSHIP
}

\author{
by \\ Gargi Sawhney \\ B.A., August 2005, University of Delhi, India \\ B.A., August 2008, Northeastern Illinois University \\ M.S., May 2011, Illinois Institute of Technology
}

A Dissertation Submitted to the Faculty of

Old Dominion University in Partial Fulfillment of the

Requirement for the Degree of

DOCTOR OF PHILOSOPHY

PSYCHOLOGY

OLD DOMINION UNIVERSITY

August 2016

Approved by:

Konstantin P. Cigularov

(Director)

Debra A. Major (Member)

M. Lance Frazier (Member) 


\begin{abstract}
EXAMINING ATTITUDES, NORMS, AND CONTROL TOWARD SAFETY BEHAVIORS AS MEDIATORS IN THE LEADERSHIP-SAFETY MOTIVATION RELATIONSHIP
\end{abstract}

\author{
Gargi Sawhney \\ Old Dominion University, 2016 \\ Director: Dr. Konstantin P. Cigularov
}

Research on occupational safety has been on the rise in recent years, owing to the high rates of deaths and disabilities that occur in the workplace. Findings suggest that unsafe behaviors and work-related accidents and injuries can be reduced through increasing employee safety motivation. Additional research has recognized leadership as a source of employee safety motivation. However, most studies have empirically assessed safety motivation and its antecedents using a cross-sectional design. Therefore, the aims of the current study were to examine effects of various safety-specific leader behaviors, following the full-range leadership model, on safety motivation using a time-lagged study design. Next, using theory of planned behavior as a theoretical framework, the present study examined the role of three mediating mechanisms, namely, attitudes, norms, and control toward safety behaviors, in the relationship between safety-specific leader behaviors and safety motivation. It was hypothesized that safetyspecific transformational, contingent reward, and management-by-exception active leadership would be positively related to safety motivation, whereas management-by-exception passive and laissez-faire leadership would be negatively related to safety motivation. In addition, it was proposed that the five leadership dimensions would exhibit an indirect relationship with employee safety motivation through their influence on attitudes, norms, and control toward safety behaviors. 
The sample for this study consisted of 168 members from Amazon's Mechanical Turk who were employed in high-risk industries and occupations. Participants completed the survey at two points in time, separated by three months. Results indicated that while transformational, contingent reward, and management-by-exception active leadership were positively related to safety motivation, management-by-exception passive and laissez-faire leadership did not exhibit any relationship with safety motivation. Furthermore, safety attitudes mediated the relationship between leader behaviors and safety motivation for transformational and management-byexception active leadership. Safety norms were found to mediate the relationship between all leadership dimensions and safety motivation. Safety control did not mediate the leadership safety motivation relationship for any of the five leadership dimensions. The findings of this study bolster support for importance of active leader behaviors in impacting employee safety motivation, as well as highlight the need for leadership development for enhancing employee safety performance. 
Copyright, 2016, by Gargi Sawhney and Old Dominion University, All Rights Reserved. 
To my husband, Ashish, for being my rock and always believing in me. 


\section{ACKNOWLEDGEMENTS}

I would like to express my sincere gratitude to my dissertation chair and academic advisor, Dr. Konstantin Cigularov. His mentorship was paramount in developing me into an independent, confident researcher. I am indebted for his tremendous support, guidance, and persistence throughout my graduate career. I am grateful for his invaluable time and efforts that he has invested in me, and for the challenging opportunities he has provided to help me grow.

I would also like to acknowledge my committee members, Dr. Debra Major and Dr. Lance Frazier for their time and insightful comments in the preparation of my dissertation. I was extremely fortunate to have a such a supportive committee.

Further, I am grateful to Dr. Richard Landers, who made the tedious task of data collection an enjoyable experience by graciously assisting with Amazon's Mechanical Turk. I would like to thank Dr. DeWayne Moore for sharing his statistical expertise when I needed it the most. I would like to extend my gratitude to Dr. Ted Scharf, who took an active interest in my research back in 2011, and continues to be a mentor.

My time at ODU would not have been the same without the extraordinary support of the Department of Psychology's office staff, Mary, Peggy, and Linda. Their continuous commitment to the graduate students is highly appreciated.

I would like to thank my parents, Sugandhi, and Ashish for their endless support during my entire graduate career. Last, but not least, I am grateful to all those who provided generous financial contributions to fund data collection for this project. 


\section{TABLE OF CONTENTS}

LIST OF TABLES. viii

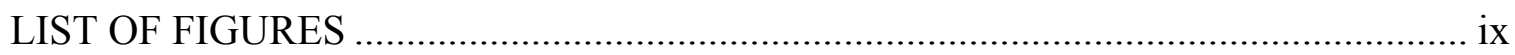

Chapter

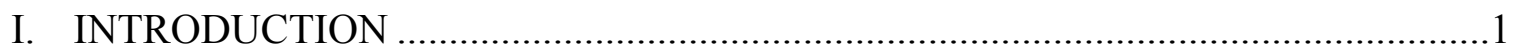

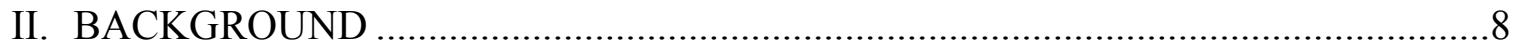

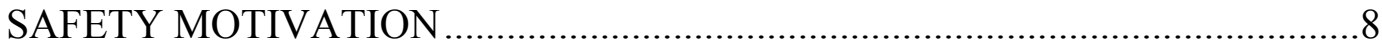

THE ROLE OF LEADERSHIP IN OCCUPATIONAL SAFETY ………..............9

FULL-RANGE LEADERSHIP MODEL AND OCCUPATIONAL SAFETY ....10

FULL-RANGE LEADERSHIP MODEL AND SAFETY MOTIVATION ..........15

MEDIATIONAL MECHANISMS IN THE SAFETY-SPECIFIC

LEADERSHIP-MOTIVATION RELATIONSHIP............................................18

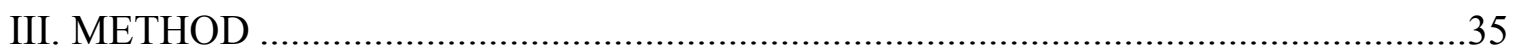

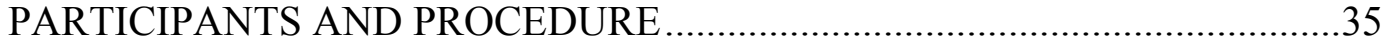

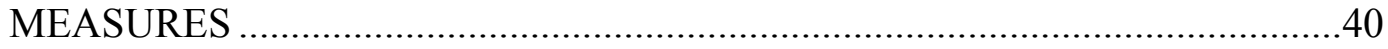

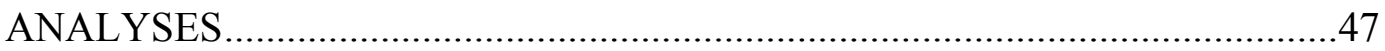

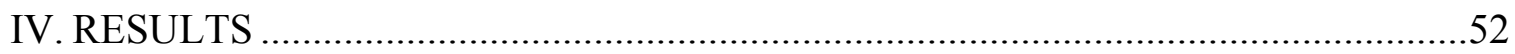

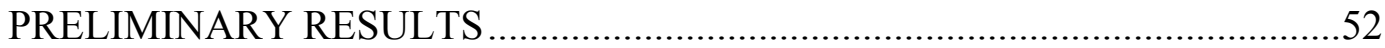

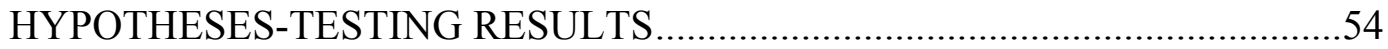

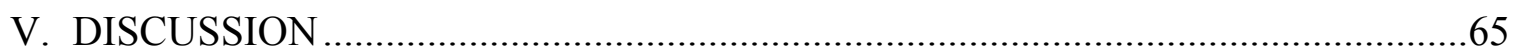

IMPLICATIONS FOR RESEARCH AND PRACTICE......................................70

STRENGTHS, LIMITATIONS, AND FUTURE DIRECTIONS..........................73

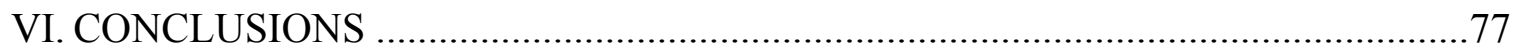

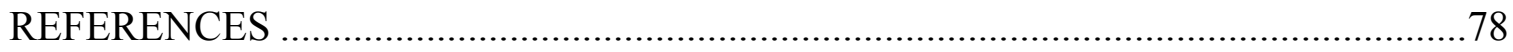

APPENDICES

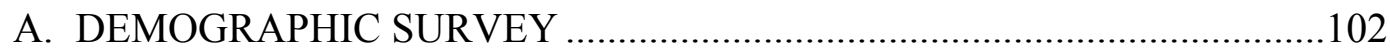

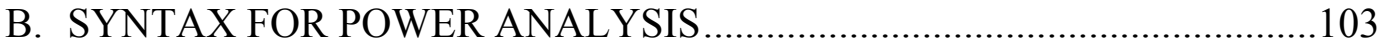

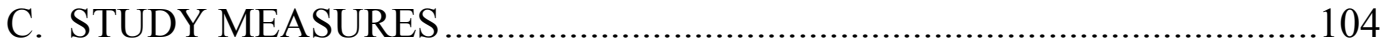

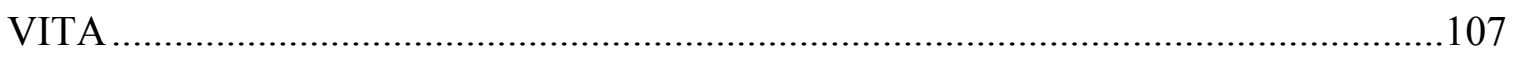




\section{LIST OF TABLES}

Table

Page

1. Demographic and background characteristics of the overall sample..........................37

2. Means, standard deviations, reliabilities, and correlations for study variables ...........57

3. Standardized coefficients and bootstrap intervals for indirect effects .......................66 


\section{LIST OF FIGURES}

Figure

Page(s)

1. Overview of the hypothesized mediation model ..................................................

2. Summary of standardized path coefficients for safety-specific transformational leadership

3. Summary of standardized path coefficients for safety-specific contingent reward leadership

4. Summary of standardized path coefficients for safety-specific management-by-exception active leadership

5. Summary of standardized path coefficients for safety-specific management-by-exception passive leadership.

6. Summary of standardized path coefficients for safety-specific laissez-faire leadership 


\section{CHAPTER I}

\section{INTRODUCTION}

Research on occupational safety has been on the rise in recent years (Huang, Chen, \& Grosch, 2010), owing to the high rates of deaths and disabilities that occur in the workplace (Christian, Bradley, Wallace, \& Burke, 2009). In 2012 alone, 4,383 fatal occupational injuries, in addition to the nearly 3 million non-fatal workplace injuries and illnesses, were reported in the U.S. (U.S. Bureau of Labor Statistics [BLS], 2013a). Of all non-fatal injuries and illnesses, $1,153,980$ cases were associated with days away from work (BLS, 2013b).

Although the incidence rates of fatal and non-fatal occupational injuries have lowered from previous years, these statistics remain of concern to both employees and organizations due to the costs associated with them. It has been estimated that occupational injuries cost organizations more than 50 billion dollars in worker compensation costs every year (Liberty Mutual Research Institute for Safety, 2012). In addition to the extravagant direct costs, the Occupational Safety and Health Administration (OSHA) highlights the indirect costs, such as training of new workers and schedule delays, which are often overlooked and may prove to be overly expensive to the organization (U.S. Department of Labor, n.d.). Last, but not least, quality of life costs deserve attention. A study reported that $38 \%$ of the surveyed workers' compensation claimants that incurred upper extremity cumulative trauma disorders, such as carpal tunnel syndrome, reported job loss, and approximately half indicated family problems (Keogh, Nuwayhid, Gordon, \& Gucer, 2000).

Organizations can reduce work-related accidents and injuries through improving employee safety behaviors (Clarke, 2006). Safety behaviors are often conceptualized as consisting of two components, namely, safety compliance and safety participation (Griffin \& 
Neal, 2000). While safety compliance includes behaviors that need to be performed by employees as part of their jobs to maintain a safe work environment (e.g., following safety rules and wearing personal protective equipment), safety participation encompasses voluntary safety behaviors that are not required by the organization, but enhance the safety environment within the organization (e.g., attending non-mandatory safety meetings and encouraging co-workers to follow safety practices). Research in occupational safety and health has deemed safety behaviors vital for predicting work-related accidents and injuries, with both compliance with safety policies and participation in safety behaviors exhibiting significant negative relationships with incidence rates of accidents and injuries (Christian et al., 2009).

Employee safety behaviors within an organization can be directly enhanced in two primary ways. First, organizations can ensure that employees have the necessary knowledge and skills to perform their jobs safely, which can be achieved through safety training (Smith-Crowe, Burke, \& Landis, 2003). And second, safety behaviors can be increased through the enhancement of employee safety motivation (Ford \& Tetrick, 2008). It has long been argued that safety behaviors are likely to be determined by safety motivation since employees are expected to possess the knowledge and skills to perform their day-to-day work activities (Andriessen, 1978). In their model of safety performance, Neal, Griffin, and Hart (2000) proposed both safety knowledge and safety motivation to be direct antecedents of safety compliance and safety participation. More recently, meta-analytic findings have supported this model (Christian et al., 2009), establishing the important role of safety motivation as a determinant of safety behaviors. More specifically, the researchers revealed significant and similar in strength effects of safety motivation and knowledge on safety behaviors; however, safety motivation, but not safety knowledge, predicted accidents and injuries (Christian et al., 2009). These findings and the fact 
that only five studies in the above-cited meta-analysis examined safety motivation (compared to nine for safety knowledge) highlight the need for more research on understanding and enhancing employee safety motivation. More specifically, more research is needed to identify the antecedents of safety motivation, which will help uncover the processes through which employees are motivated to perform in a safe manner.

Although safety motivation has been regarded essential in predicting safety behaviors (see Christian et al., 2009), a number of methodological weaknesses prevail in the occupational safety literature with respect to measurement and study design involving this construct. While a number of studies have empirically assessed safety motivation and its antecedents (Andriessen, 1978; Brosseau \& Li, 2005; Dal Corso, 2008; Johnson \& Hall, 2005; Neal et al., 2000; Vinodkumar \& Bhasi, 2010; Wills, Watson, \& Biggs, 2009), several of these studies have leveraged measures that assess safety attitudes as opposed to safety motivation (e.g., Dal Corso, 2008; Neal \& Griffin, 2006; Neal et al., 2000). With respect to study design, studies have predominantly relied on cross-sectional approaches to examine this construct (e.g., Johnson \& Hall, 2005; Neal et al., 2000). In fact, only one study has utilized longitudinal design to investigate the antecedents of safety motivation (Neal \& Griffin, 2006).

Leadership has been recognized as a source of motivating employees to perform their work safely (Hofmann \& Morgeson, 2004; Zohar, 2011). Leaders influence safety compliance and participation "by generating motivation to achieve positive change and prioritizing employee well-being” (Inness, Turner, Barling, \& Stride, 2010, p. 280). While safety motivation has been recognized as a proximal antecedent of safety behaviors, leadership is considered a distal predictor (Christian et al., 2009). In fact, research findings indicate a positive relationship between leader behaviors and safety motivation (Christian et al., 2009; Conchie, 2013). 
While meta-analytic findings affirm the effect of leadership on employee safety motivation (Christian et al., 2009), this research is scant. So far, only two studies have used a broad range of leader behaviors to evaluate the link between leadership and safety motivation (Lee, Almanza, Jang, Nelson, \& Ghiselli, 2013; Zacharatos, Barling, \& Iverson, 2005). Due to the multidimensional nature of the leadership construct (Bass, 1985), "different aspects of leadership may affect safety in different ways and for different reasons" (Hoffmeister et al., 2014, p. 68). Hence, rather than assessing leadership as a unidimensional construct, it is crucial to study the impact of different leader behaviors on employee safety motivation. Additionally, researchers who have considered broad measures of leadership have utilized measures of general leader behaviors as opposed to safety-specific leader behaviors when studying safety motivation (Lee et al., 2013). Evidence suggests that although general and safety-specific leadership may be related, safety-specific leadership may account for additional variance in safety outcomes, above and beyond the variance explained by general leadership (Mullen \& Kelloway, 2009).

Recently, researchers have stressed the deficiency of research exploring mechanisms through which leadership affects employee safety (Mullen \& Kelloway, 2011; Zohar, 2011). Understanding of processes is vital to providing deeper insight into ways in which leaders can motivate employees to work in a safe manner. Even though the existence of motivational processes has been discussed in the safety literature (Conchie, 2013), it is surprising that only one study has proposed underlying mechanisms through which leaders affect employee safety motivation (Lee et al., 2013). While this study hypothesized positive effects of leadership on attitudes toward safety behaviors and motivation, no mediation hypotheses were tested by the researchers. Therefore, there is a pressing need to explore the processes through which leaders motivate employees to work safely. 
One useful approach to studying mediators in the leadership - safety motivation relationship is through the framework provided by theory of planned behavior (TPB; Ajzen, 1991). An extension of the Theory of Reasoned Action (TRA; Ajzen \& Fishbein, 1980), TPB highlights three determinants of intention (or motivation) to perform a certain behavior, namely, attitudes toward the behavior, subjective norms, and perceived behavioral control (Ajzen, 1991). TPB has been extensively used to predict a number of safety behaviors, such as proactive and compliance safety behaviors (Fugas, Silva, \& Meliá, 2012), machinery use, animal handling, fall prevention, and pesticide use (Colémont \& Van den Broucke, 2008). In addition, this framework has been utilized to examine the role of determinants on safety motivation (Brosseau \& Li, 2005; Johnson \& Hall, 2005; Wills et al., 2009). While TPB has been a popular choice in predicting safety behavior and safety motivation, there is a paucity of research examining the sources that shape the three determinants of TPB. For example, while researchers have assessed the effects of safety climate on safety attitudes, safety norms, and perceived safety control (Fugas et al., 2012; Wills et al., 2009), the role of safety-specific leader behaviors in influencing the TPB determinants of safety motivation remains unexamined.

In light of the abovementioned gaps, the current study aims to test a theoretical model illustrated in Figure 1. More specifically, using TPB as a theoretical framework, the study will investigate the effects of leadership on employee safety motivation. In addition, the present study will examine the role of three mechanisms, namely, attitudes toward safety behaviors, norms for safety behaviors, and perceived control over safety behaviors in the relationship between safetyspecific leader behaviors and safety motivation over a three-month period.

The following sections provide the theoretical and empirical foundation underlying this study. Specifically, I start out with an overview of safety motivation, and the relevance of the 
construct in the context of occupational safety. Next, research is reviewed on the effects of leadership on safety, and the full-range leadership model is introduced. Theoretical rationale and empirical evidence for the link between leadership and safety motivation are provided. Lastly, using TPB as a theoretical framework, the mediating roles of attitudes toward safety behaviors, norms for safety behaviors, and perceived control over safety behaviors are justified in the safety-specific leadership - safety motivation link. 


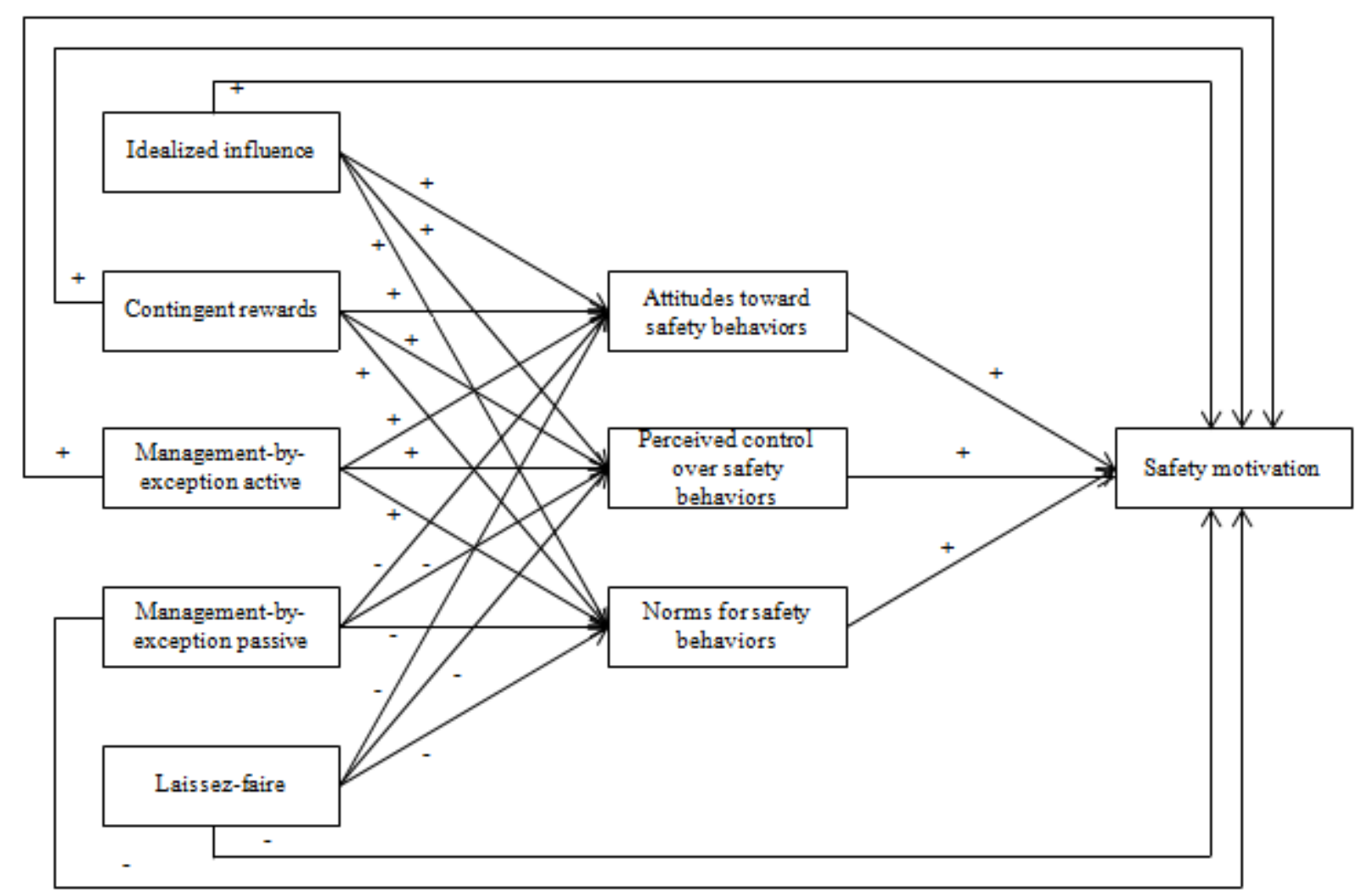

Figure 1. Overview of the hypothesized mediation model. 


\section{CHAPTER II}

\section{BACKGROUND}

\section{Safety Motivation}

Motivation is the combined effect of 1) the choice to expend effort, 2) the amount of effort to expend, and 3) the duration for which the effort is expended, resulting from the interaction of individual and external factors (Latham \& Pinder, 2005; Pinder, 1998). Accordingly, safety motivation refers to the "arousal, direction and persistence of behavior that reduces the likelihood of occupational injury or illness" (Lingard, 2002, p. 265). More recently, Neal and Griffin (2006) characterized the construct of safety motivation as "an individual's willingness to exert effort to enact safety behaviors and the valence associated with those behaviors" (p. 947). For the purposes of the current study, safety motivation will be defined as employees' willingness to perform their work in a safe manner.

Motivation has been long recognized as a key determinant of job performance (Burke, Sarpy, Tesluk, \& Smith-Crowe, 2002). In Campbell's (1990) model of job performance, motivation is regarded as a proximal determinant of job performance alongside declarative knowledge and procedural knowledge and skills. Griffin and Neal (2000) argued that the constructs of job performance and safety performance could be conceptualized in a similar manner, suggesting that Campbell's model could be adapted to safety performance. Specifically, these authors proposed that safety behaviors, which they equate to safety performance, are determined by two proximal predictors: safety knowledge and skills and safety motivation. According to Ford and Tetrick (2008), in the absence of "an organizational environment that is conducive to safety behaviour, knowledge and skills may be insufficient to result in safe performance, since individuals may not be motivated to carry out the safety-related behaviors 
that they have learned and are capable of performing" (p. 1473). Stated differently, unless employees are motivated to work in a safe manner, safety knowledge and skills may have little, if any, impact on ensuring workplace safety.

Empirical findings attest to the important role safety motivation plays in improving safety behaviors and reducing the likelihood of experiencing occupational accidents and injuries. Significant positive relationships have been observed between employee safety motivation and their safety behaviors across different industries, such as chemical (Vinodkumar \& Bhasi, 2010), healthcare (Dal Corso, 2008; Neal \& Griffin, 2006; Neal et al. 2000), manufacturing (Griffin \& Neal, 2000), and petroleum and telecommunications (Zacharatos et al., 2005), among others. In fact, meta-analytic evidence has established a strong, positive correlation between safety motivation and safety behaviors $\left(\mathrm{M}_{\rho}=.57\right)$, as well as a significant negative correlation between safety motivation and accidents/injuries $\left(\mathrm{M}_{\rho}=-.20\right.$; Christian et al., 2009).

\section{The Role of Leadership in Occupational Safety}

Leadership has emerged as an important construct in safety research (Griffin \& Talati, 2014; Martínez-Córcoles, Gracia, Tomás, Peiró, \& Schöbel, 2013; Mullen \& Kelloway, 2011). A number of leader behaviors, such as safety feedback (Zohar, 2000), supervisor support (Parker, Axtell, \& Turner, 2001), behavioral integrity (Halbesleben et al., 2013), and communication (Zohar \& Polachek, 2014) have been identified as effective in enhancing safety behaviors and reducing accidents and injuries in the workplace. Additionally, findings from meta-analyses have consistently provided corroborating evidence for the role of leadership in predicting safety behaviors and safety outcomes (Christian et al., 2009; Clarke, 2013; Nahrgang, Morgeson, \& Hofmann, 2011). Corrected mean correlations of leadership with safety compliance and safety participation have ranged between .24 and .59 and .35 and .44 , respectively. Similarly, a 
corrected mean correlation of -.14 was reported between leadership and accidents and injuries (Nahrgang et al., 2011).

Although leadership has received significant research attention in the occupational safety and health literature, safety-specific leadership has been less frequently studied (Clarke, 2013). According to Zohar (2002a), the constructs of job performance and safety performance are not necessarily complimentary and may come at odds with each other. While safety performance prioritizes safety over productivity, job performance traditionally stresses effectiveness and productivity (Zohar, 2002b). Although general leadership may be a valid predictor of job performance where all aspects of performance or tasks are taken into account, it may not as accurately predict safety behaviors (where production goals are distinguished from safety priorities) as its safety counterpart (Zohar, 2002a). Hence, safety-specific leadership theories may be more useful in predicting safety behaviors as opposed to general theories of leadership. Empirical evidence has corroborated these assertions. Specifically, a study cited in Mullen and Kelloway (2009) reported that safety-specific leadership accounted for variance above and beyond general leadership in predicting safety outcomes. In addition, aspects of safety-specific leadership, such as safety inspiring and safety monitoring (Griffin \& Hu, 2013), as well as leader safety concern (Lu \& Yang, 2010), have been positively associated with safety behaviors. Hence, the proposed study focuses on the effects of safety-specific leadership on safety motivation.

\section{Full-Range Leadership Model and Occupational Safety}

A leadership theory that has been often employed in the occupational safety and health literature is the Full-Range Leadership model (FRL; Bass, 1985). The FRL model encompasses three groups of leader behaviors, namely, transformational, transactional, and laissez-faire. A 
transformational leader, by definition, is one who plays a part "in enlarging and elevating followers' motivation, understanding, maturity, and sense of self-worth" (Bass, 1997, p. 130). This type of leadership is characterized by charisma or idealized influence, inspirational motivation, individualized consideration, and intellectual stimulation.

Idealized influence describes leaders as self-sacrificing for the benefit of the individual or group (Bass, 1985). These leaders demonstrate high standards for ethical and moral conduct. Behaviors and attributes displayed by charismatic leaders include self-confidence, charisma, risk-taking, and self-determination (Bass \& Riggio, 2006). Through idealized influence, leaders establish themselves as role models for the followers and try to gain their trust. These leaders instill a sense of pride in their followers for being associated with them. On their part, the followers try to emulate their leaders. In the context of occupational safety, these leaders prioritize safety rather than giving in to productivity pressures (Barling, Loughlin, \& Kelloway, 2002). They become role models by conveying "occupational safety as a core value through their own personal commitment, thereby facilitating higher levels of followers' trust in management and organizational loyalty" (Barling et al., 2002, p. 489).

Inspirational motivation, a second dimension of transformational leadership, describes leaders who clearly articulate the vision of the organization and demonstrate optimism and enthusiasm towards meeting the organizational goals. These leaders encourage employees by presenting them with challenging goals, providing clear identification with organizational goals, and communicating how employees can meet these organizational goals (Avolio, 1999; Bass \& Riggio, 2006). Using inspirational motivation, leaders inspire and motivate followers to become committed to a shared vision (Bass, 1985). They motivate their followers to go beyond their individual interests and work towards collective goals by communicating high expectations of 
them. In the context of occupational safety, these leaders can promote safety by convincing their employees that they are capable of achieving high safety standards (Barling et al., 2002). Through inspirational motivation, leaders can "challenge individuals to go beyond their needs for the collective good and to achieve a level of safety performance that surpasses the minimum safety standards or that was once perceived to be unattainable" (Mullen, Kelloway, \& Teed, 2011, p. 43).

A third dimension of transformational leadership, individualized consideration, reflects the degree to which the leader provides a supportive climate for employees and listens to their individual needs (Avolio, 1999; Bass \& Riggio, 2006). These leaders coach and mentor individual employees in an effort to help them become fully actualized. Leaders who exhibit individualized consideration will prioritize the safety and well-being of their employees. Due to their inclination towards employee safety, they are likely to provide timely feedback related to employees' safety behaviors, as well as respond to employees' safety concerns in a timely manner (Mullen \& Kelloway, 2009).

The last dimension of transformational leadership, intellectual stimulation, describes the leader as one who stimulates employees to be creative and innovative (Bass, 1985). Further, this leader solicits employees' perspectives on problems and considers a wide array of options before making decisions. Through intellectual stimulation, leaders stimulate followers to think about problems in new ways. They encourage followers to challenge old assumptions while developing creative solutions (Avolio, 1999; Bass \& Riggio, 2006). In the context of safety, leaders demonstrate intellectual stimulation by pushing followers to think of innovative ways to deal with safety issues and enhance workplace safety (Barling et al., 2002). 
Transformational leadership has received much attention in the occupational safety literature. Meta-analytic research suggests that transformational leadership is positively related to favorable outcomes, such as safety climate and safety performance, as well as negatively related to unfavorable outcomes, such as injuries (Clarke, 2013). For instance, in a study of nursing assistants, Lee, Coustasse, and Sikula (2011) found negative associations between transformational leadership and workplace injuries and injury-related absenteeism. Similarly, in another study, transformational leadership was positively related to both safety-specific trust and safety citizenship behaviors (Conchie \& Donald, 2009). A recent study also found that the four transformational leader behaviors were individually positively associated with safety compliance and participation, and negatively associated with injury and pain (Hoffmeister et al., 2014).

Unlike transformational leadership, the focus of transactional leadership is primarily on the exchanges between leaders and followers (Burns, 1978). Transactional leadership comprises of three dimensions, namely, contingent reward, management-by-exception active (MEA), and management-by-exception passive (MEP; Bass, 1985). Contingent reward refers to the exchange between the leader and the employees in which the effort put forth by the employees is exchanged for rewards, such as job security, promotion, and monetary incentives. Leaders practicing contingent reward frame employees' goals based on the goals of the organization, and assist individual employees in achieving those goals. Through contingent reward behaviors, leaders can promote occupational safety by providing incentives to individuals for performing their work safely. For example, to reinforce safety behaviors, leaders can provide recognition to employees that perform their jobs in a safe manner. Empirical evidence suggests that leader contingent reward behaviors have effects on employee safety outcomes. Specifically, using a 
sample of metal processing workers, Zohar, (2002b) showed that contingent reward behaviors negatively predicted injury rate.

A leader exercising MEA employs corrective criticism, negative feedback, and negative reinforcement (Howell \& Avolio, 1993). This leader monitors employee behaviors to detect deviances before they occur (Bass \& Riggio, 2006). In cases where an employee prioritizes productivity over safety, a leader practicing MEA will point out the safety procedures that the employee may have disregarded. For instance, this leader is likely to call out an employee who is neglecting to adhere to rules regarding wearing personal protective equipment in the workplace. Empirical evidence corroborating the influence of MEA on safety criteria is scant. However, a study found significant effects of supervisory monitoring behavior on reduced injury incidence and injury risk (Huang, Chen, Krauss, \& Rogers, 2004).

The third dimension of transactional leadership is management-by-exception passive (MEP; Bass, 1985). Passive leaders intervene only after a problem has either been brought to their attention or become serious enough to demand attention (Bass, 1991). In the context of safety, these leaders will only intervene after a safety-related incident has occurred on the job. Specifically, these leaders are likely to mandate safety behavior only in the event of a serious injury or death of an employee due to negligence of safety procedures in the workplace. While few researchers have empirically assessed the impact of passive leadership on safety outcomes (Mullen \& Kelloway, 2011), existing research suggests a negative relationship between MEP leadership and safety outcomes. A research endeavor by Kelloway, Mullen and Francis (2006) illustrated that not only does passive leadership predict safety events and injuries, but this construct also incrementally predicts these outcomes above and beyond transformational leadership. 
Finally, the third group of leader behaviors in the FRL model is characterized by avoidant leader behaviors, better known as laissez-faire or non-leadership. These leaders exhibit indecisiveness and abdication of responsibility (Antonakis, Avolio, \& Sivasubramanian, 2003; Bass, 1997). Additionally, they display indifference towards their subordinates (Pihie, Sadeghi, \& Elias, 2011). A laissez-faire leader is likely to ignore any safety issues in the workplace. In the event of a workplace accident, these leaders are unlikely to intervene while placing responsibility of the accident entirely on the employee. In fact, extant research reported a negative, albeit, nonsignificant relationship between laissez-faire leadership and injury rate (Zohar, 2002b).

\section{Full-Range Leadership Model and Safety Motivation}

Leadership has been defined as the process through which an individual inspires and influences others to achieve a common goal (Northouse, 2012). Leaders transform employees by "instilling self-motivation and confidence in people and empowering them to develop their own competence to lead" (Othman \& Wanlabeh, 2012, p. 240). As has been suggested by Rabey (2001), the ingredients of motivation lie within the individual. The role, then, of the leader is to cultivate prospects to stimulate employee motivation.

Transformational leaders are characterized as "exceptional leaders who have extraordinary effects on their followers" (Shamir, House, \& Arthur, 1993, p. 577). By engaging in idealized influence, inspirational motivation, individualized consideration, and intellectual stimulation behaviors, safety leaders increase employee safety motivation. Specifically, through idealized influence, safety leaders "raise the salience of certain values and collective identities in followers' self-concepts and articulate the goals and the required efforts in terms of those values identities" (Shamir, Zakay, Breinin, \& Popper, 1998, p. 388). Furthermore, these leaders motivate employees by arousing "feelings of admiration" (Michel, Wallace, \& Rawlings, 2013) 
and by establishing themselves as role models (Bass \& Riggio, 2006). Similarly, safety leaders that practice inspirational motivation enhance employee safety motivation by providing meaning and challenge to the work of employees (Elenkov, Judge, \& Wright, 2005). These leaders convincingly convey their confidence in their employees to achieve high safety standards (Barling et al., 2002). Using individualized consideration, leaders show genuine concern for the safety and well-being of their employees (Barling et al., 2002). Further, transformational leaders enhance employee motivation by concentrating on individual development while acknowledging individual strengths (Bass, Avolio, Jung, \& Berson, 2003). Leaders exhibiting intellectual stimulation motivate employees by arousing problem-solving in followers (Bass et al., 2003).

In sum, through four different groups of behaviors (i.e., idealized influence, inspirational motivation, individualized consideration, and intellectual stimulation), safety-oriented transformational leaders can push followers to engage in safety behaviors that go beyond organizational expectations (Wang, Oh, Courtright, \& Colbert, 2011). In fact, a recent study reported a significant positive correlation between safety-specific transformational leadership and employee safety motivation in two samples of construction employees (Conchie, 2013). Thus, it is hypothesized that:

Hypothesis 1a: Safety-specific transformational leadership will be positively related to employee safety motivation.

Unlike transformational leaders, transactional leaders place emphasis on the goals of the individual. Specifically, rather than focusing on organizational and higher-level personal goals (Vandenberghe, Stordeur, \& D'hoore, 2002), transactional leaders motivate employees by encouraging them to augment self-interests and benefits (Epitropaki \& Martin, 2005). For instance, by displaying contingent reward behaviors, leaders can motivate employees to comply 
with safety policies by setting certain safety standards, providing incentives for compliance, and punishing those who are out of compliance with those standards (Bass \& Avolio, 1997). While no study has examined the relationship between safety-specific contingent reward behaviors and safety motivation, meta-analytic evidence suggests a correlation of .59 between contingent reward and employee motivation in non-safety contexts (Judge \& Piccolo, 2004). Leaders can also motivate employees by engaging in MEA behaviors (Bass, 1985). These leaders closely monitor "followers for any deviances, mistakes and errors so that corrective action can be taken as soon as possible" (Groves \& LaRocca, 2011, p. 513), thus enhancing employee motivation. Once again, although no research exists on the link between safety-specific MEA and safety motivation, meta-analytic results provide evidence for a positive relationship between the two constructs in non-safety settings $\left(\mathrm{M}_{\rho}=.14\right.$; Judge \& Piccolo, 2004).

Unlike contingent reward and MEA behaviors, leaders exhibiting MEP behaviors "communicate the message that safety is not important" (Mullen \& Kelloway, 2011, p. 361). In turn, followers of these leaders are not motivated to portray safety behaviors since they do not perceive safety to be essential in performing their jobs. Although no study has investigated the link between safety-specific MEP and safety motivation, there is meta-analytic evidence of a negative relationship between MEP and general motivation $\left(\mathrm{M}_{\rho}=-.27\right.$; Judge \& Piccolo, 2004). Given the above, the following hypotheses are posited:

Hypothesis $1 b$ : Safety-specific contingent reward leadership will be positively related to employee safety motivation.

Hypothesis 1c: Safety-specific management-by-exception active leadership will be positively related to employee safety motivation. 
Hypothesis 1d: Safety-specific management-by-exception passive leadership will be negatively related to employee safety motivation.

Similar to leaders that portray MEP behaviors, laissez-faire leaders tend to demotivate employees by evading responsibilities (Lievens, Van Geit, \& Coetsier, 1997; Ryan \& Tipu, 2013). The lack of attention toward safety issues on the part of these leaders is likely to lead to frustration on the part of the employees (McColl-Kennedy \& Anderson, 2005), thus reducing employees' safety motivation. Empirical research has yet to establish the link between laissezfaire leader behaviors and safety motivation. However, meta-analytic research shows a negative, albeit non-significant, relationship between general laissez-faire leadership and employee motivation (Judge \& Piccolo, 2004). Consequently, the proposed study poses the following hypothesis:

Hypothesis 1e: Safety-specific laissez-faire leadership will be negatively related to employee safety motivation.

\section{Mediational Mechanisms in the Safety-Specific Leadership-Motivation Relationship}

Although empirical evidence suggests that leaders significantly impact employees' safety motivation (e.g., Christian et al., 2009), there is a lack of theoretical rationale for how leaders motivate employees to perform their jobs safely. Specifically, with the exception of Lee et al. (2013), no study to date has attempted to explain the underlying mechanisms through which leadership affects safety motivation. The larger literature on leadership and motivation, however, has justified the existence of mediators in the relationship of the two constructs (Kark \& Van Dijk, 2007), which can be utilized to bridge this gap in the occupational safety literature.

In the last couple of decades, a few researchers have attempted to provide theoretical rationale for the relationship between leadership and motivation using motivational theories (e.g., 
Isaac, Zerbe, \& Pitt, 2001; Kark \& Van Dijk, 2007; Lee et al., 2013; Shamir et al., 1993). A number of theories of motivation have been used as frameworks to explain the process through which leaders influence employee motivation, such as self-concept theory (Shamir, 1991), expectancy theory (Vroom, 1964), goal-setting theory (Locke, 1968), and reinforcement sensitivity theory (Gray, 1970). A viable theory that can be utilized as a conceptual framework to identify mechanisms through which safety-specific leadership affects safety motivation of employees is the theory of planned behavior (TPB, Ajzen, 1991), which is an extension of theory of reasoned action (Ajzen, 1988). A description of TPB and its relevance to the topic at hand, as well as theoretical and empirical rationales for mediation hypotheses are presented next.

Theory of planned behavior and safety motivation. A fundamental component of TPB is behavioral intentions, which are a direct antecedent of behavior and can be defined as the willingness to engage in a particular behavior (Fishbein, 2008). In the safety context, safety intentions would be considered a direct antecedent of safety behaviors, capturing the construct of safety motivation (Ajzen, 1991). Consequently, for the purposes of the proposed study, safety motivation will be used to represent the construct of safety intentions as conceptualized in TPB. Safety motivation will reflect employees' willingness to expend effort to engage in safety behaviors.

In addition to proposing a direct relationship between intentions (i.e., motivation) and behavior, TPB postulates three independent determinants of motivation, namely, attitudes toward the behavior, subjective norms, and perceived behavioral control. Attitudes are defined as the positive or negative appraisal of the behavior in question. Stated differently, attitudes reflect salient beliefs individuals hold regarding specific behaviors (Fishbein \& Ajzen, 1975). Following the above definition, attitudes toward safety behaviors can be conceptualized as salient beliefs 
and feelings individuals hold regarding safety behaviors. Subjective norms represent the degree of pressure perceived by an individual to perform a certain behavior (Ajzen \& Madden, 1986). In the context of safety, safety norms can be defined as the perceived social pressure to engage in safety behaviors. Lastly, perceived behavioral control reflects an individual's perceptions regarding the "ease or difficulty of performing a behavior and it is assumed to reflect past experience as well as anticipated impediments and obstacles" (Ajzen, 1991, p. 188). Individuals who trust that they have the essential resources and opportunities to perform a certain behavior are likely to form strong intentions to perform that behavior (Giles \& Larmour, 2000). Safety control can then be defined as an individual's perceptions regarding their ability to perform safety behaviors.

Meta-analytic evidence has shown the utility of TPB to adequately predict both motivation and behavior across different contexts (Ajzen, 1991; Armitage \& Conner, 2001). Specifically, Ajzen (1991) reported an average correlation of .71 between the three determinants (i.e., attitude toward the behavior, subjective norms, and perceived behavioral control) and intention. Additionally, Armitage and Conner correlated attitudes, norms, and perceived behavioral control with intentions and behavior, and found correlations of .57 and .55 , respectively. Even within the organizational domain, TPB has successfully predicted various work-related motivations. For instance, a study by Van Breukelen, Van Der Vlist, and Steensma (2004) suggested that the three determinants significantly predicted intentions to turnover. In another study, the determinants accounted for a total of $65 \%$ of the variance in intention to apply for promotion (Giles \& Larmour, 2000).

Within the last decade, TPB has been utilized in occupational safety research to predict safety motivations in the workplace, such as driving intention (Wills et al., 2009) and intent to 
lift safely (Johnson \& Hall, 2005). Additionally, safety behaviors, such as safety compliance and proactive safety practices (Fugas et al., 2012) and safe-lifting behaviors (Johnson \& Hall, 2005), and driver behaviors (Wills et al., 2009) have been examined using the TPB framework.

Although leadership has been identified as a potential source of safety motivation for employees (Christian et al., 2009), the specific mechanisms through which safety-specific leadership influences employee safety motivation (i.e., safety behavior attitudes, subjective safety norms, and perceived safety control), as proposed by TPB, have not been tested yet. Since research suggests the existence of mediators in the leadership-safety relationship (Zohar, 2011), it is worthwhile to examine the abovementioned TPB determinants as mechanisms through which safety-specific leadership impacts employee safety motivation.

Attitudes towards safety behaviors as a mediator. Attitudes toward safety behaviors have garnered much interest in the occupational safety literature. In a qualitative interview study of construction workers and first-line managers, attitudes toward safety were identified as fundamental to high safety standards in the construction industry (Törner \& Pousette, 2009). Empirical research has also attested to the significance of these attitudes in predicting safety behaviors and outcomes. For instance, such attitudes have been found to be positively related to safety behaviors (Ji, You, Lan, \& Yang, 2011) and safety outcomes (Joseph, Reddy, \& Sharma, 2013). Only one study, thus far, has examined, and found support for a positive relationship between attitudes toward safety behaviors and safety motivation (Lee et al., 2013).

In the workplace, the "social environment provides cues which individuals use to construct and interpret events," as well as "provides information about what a person's attitudes and opinions should be" (Salancik \& Pfeffer, 1978, p. 226). In fact, leaders have often been credited as an organizational source of influence that can promote employee attitudes 
(Walumbwa, Hartnell, \& Oke, 2010). According to McCabe, Loughlin, Munteanu, Tucker, and Lam (2008), individuals have a tendency to internalize views and opinions of people that they associate with, such as their immediate supervisors or leaders.

Researchers have argued that transformational leaders can shape employee attitudes in a number of ways, such as articulating a vision, role modeling, and providing support (Bommer, Rich, \& Rubin, 2005). Transformational leaders articulate a vision, thereby communicating goals for a better future. By conveying priority of safety for the welfare of employees, transformational leaders can promote favorable attitudes toward safety within employees. Similarly, transformational leaders become role models for subordinates (Bommer et al., 2005). Additionally, these leaders portray themselves as similar to their subordinates (Gardner \& Avolio, 1998). Transformational leaders that enact safety behaviors are likely to be conceived as trustworthy and committed to safety, thereby evoking positive attitudes toward safety behaviors that subordinates strive to emulate (Bommer et al., 2005).

Transformational leaders can also impact employee attitudes by providing individualized support (Bommer et al., 2005). By showing concern for safety of individual employees, as well as reinforcing value of safety, these leaders can strengthen employee attitudes toward safety behaviors. Thus far, only one study has examined the impact of safety-specific transformational leadership on safety attitudes using a cross-sectional design and found a non-significant relationship (Lee et al., 2013).

As previously suggested, safety transactional leadership rests on the premise that leaders reward subordinates for meeting safety standards, while punishing them when these standards are unmet (Howell \& Avolio, 1993). Through contingent reward behaviors, safety leaders help employees see the relationship between safety behavior and rewards for safety (Boseman, 2008). 
Additionally, by reinforcing the relationship between safety behaviors and rewards, and fulfilling employee expectations pertaining to receiving rewards for safety, these leaders strengthen employee beliefs that rewards will follow performance of safety behaviors (Chiaburu, Diaz, \& Pitts, 2011). Leaders exhibiting contingent reward behaviors thus influence safety attitudes through rewards, since "rewards are a powerful tool to demonstrate to the follower what the leader wants" (Boseman, 2008, p. 37). When employees deem rewards for safety behaviors as acceptable, there is potential for emotional attachment towards the leader (Mester, Visser, Roodt, \& Kellerman, 2003), which can further impact safety attitudes of employees.

Similarly, MEA leaders clarify which behaviors are desired in the workplace (Podsakoff, Bommer, Podsakoff, \& MacKenzie, 2006). When employees understand "that some behaviors are rewarded by the leader and some are punished, it clarifies their understanding of what the leader would like them to do" (p. 116), thereby reducing role ambiguity and enhancing job attitudes. Therefore, by criticizing employees for neglecting to perform safety behaviors, leaders can establish the importance of working safely and hence increasing favorable attitudes in employees toward safety behaviors. While no published research exists examining the relevance of contingent reward and MEA leader behaviors on attitudes toward safety behaviors, studies have confirmed positive relationships between contingent reward and MEA and work attitudes, such as affective commitment, normative commitment, and continuance commitment (Lo, Ramayah, \& Min, 2009).

Unlike MEA leaders, MEP leaders are likely to ignore undesired behaviors on the part of the employees until they become serious (Bass, 1991). Such neglectful behavior by the leader may send across the message that certain behaviors are not desired. In the context of safety, MEP leaders show lack of interest toward safety behaviors, thereby suggesting "to employees that 
occupational safety is not important and is undeserving of their attention" (Kelloway et al., 2006, p. 79). Hence, by failing to provide constructive feedback for deviant safety behaviors and to reward safety behaviors, MEP leaders may foster negative attitudes toward such behaviors. Although no research has examined the role of safety-specific MEP leader behaviors on attitudes toward safety behaviors, studies have shown a negative relationship between MEP and work attitudes, such as affective and normative commitment (Lo et al., 2009).

Contrary to safety-specific transformational, contingent reward, and MEA leader behaviors, laissez-faire behaviors are likely to exhibit a negative relationship with attitudes toward safety behaviors. In addition to being unresponsive to employees' safety needs, laissezfaire leaders withhold reinforcement for safety behaviors, as well as punishment for lack thereof. Failing to reward safety behaviors is likely to produce negative attitudes among employees, especially if employees have exhibited safety behaviors (Hinkin \& Schriesheim, 2008). Although no research has empirically demonstrated the role of safety-specific laissez-faire leadership on safety attitudes, meta-analytic evidence suggests a strong negative relationship of general laissezfaire leadership with satisfaction with leader (Judge \& Piccolo, 2004).

In accordance with TPB (Ajzen, 1991), a direct determinant of safety intention or motivation is attitude, which consists of employees' beliefs and emotions regarding safety behaviors (Neal \& Griffin, 2004). Attitudes play a crucial role in determining how an individual will process information, make decisions, and take action (Boninger, Krosnick, \& Berent, 1995). Attitudes toward safety behaviors are "a learned disposition to respond in a consistently favorable or unfavorable manner with respect to safety" (Fugas, Silva, \& Meliá, 2013, p. 841). Therefore, if employees manage to work unsafely without any negative outcomes, and suspect safety procedures to act as a hindrance to their productivity, they may form negative attitudes 
toward safety behaviors. On the contrary, employees with a positive disposition towards safety are likely to have favorable attitudes toward safety behaviors, which is likely to motivate them to perform their jobs in a safe manner (Fugas et al., 2013). Empirical evidence has been equivocal on the role of safety attitudes in predicting safety motivation. While one study reported a positive association between safety attitudes to violating approved safety standards and intention to violate (Fogarty \& Shaw, 2010), another study reported a non-significant relationship between safety attitudes and intentions to lift safely (Johnson \& Hall, 2005). An explanation for these inconsistent findings may be that safety attitudes were measured more broadly by Fogarty and Shaw, as compared to the study by Johnson and Hall.

As previously suggested, leadership has been identified as a source of attitude formation (Walumbwa et al., 2010). Therefore, it can be assumed that leaders can indirectly impact safety motivation by shaping safety attitudes of employees. A recent study of maintenance personnel examined the role of attitudes as a mediator of the relationship between management attitudes and safety violation intention, and found attitudes to partially mediate the relationship (Fogarty $\&$ Shaw, 2010). Hence, the following hypotheses are put forth:

Hypothesis 2a: Safety-specific transformational leadership will exhibit an indirect positive effect on employee safety motivation through employee attitudes toward safety behaviors.

Hypothesis 2b: Safety-specific contingent reward leadership will exhibit an indirect positive effect on employee safety motivation through employee attitudes toward safety behaviors. 
Hypothesis 2c: Safety-specific management-by-exception active leadership will exhibit an indirect positive effect on employee safety motivation through employee attitudes toward safety behaviors.

Hypothesis 2d: Safety-specific management-by-exception passive leadership will exhibit an indirect negative effect on employee safety motivation through employee attitudes toward safety behaviors.

Hypothesis 2e: Safety-specific laissez-faire leadership will exhibit an indirect negative effect on employee safety motivation through employee attitudes toward safety behaviors.

Norms for safety behaviors as a mediator. While norms for safety behaviors have been deemed essential to the safety and health of employees (Fugas et al., 2013), their effects on occupational safety have not been sufficiently explored (Tesluk \& Quigley, 2003). Only a few studies have demonstrated the relevance of safety norms in predicting proactive and compliance safety behaviors (Fugas, Meliá, \& Silva, 2011; Fugas et al., 2012). However, the relevance of safety norms in predicting safety motivation is severely lacking. This is concerning since research suggests that social norms provide guidelines to individuals for their own behavior (Ellemers, Gilder, \& Haslam, 2004).

Norms for safety behaviors can be created in a number of ways. In the workplace, norms for safety behaviors "develop gradually and informally as group members learn what behaviors are necessary for the group to function more effectively" (Feldman, 1984, p. 50). These safety norms may play a role in determining safety motivation and safety behaviors. Norm formation can also be attributed to leaders (Feldman, 1984; Taggar \& Ellis, 2007). According to Friedkin (2001), by making explicit statements, leaders can effectively set norms for safety behaviors. For 
instance, by acknowledging his positive view of safety practices, a leader may set norms for safety behaviors in the workplace.

Safety-specific transformational leaders promote safety values that are appealing to employees, as well as seek their advice on matters related to safety. Employees are drawn to these leaders, and display confidence in them (Bono \& Anderson, 2005). The quality nature of relationship between safety-specific transformational leaders and employees grants the leaders opportunities for information sharing and clarifying perceptions, thereby allowing subordinates to judge specific behaviors that are valued by the leader (Zohar, 2011). To ensure that their behaviors are consistent with that of the leader, subordinates emulate safety behaviors that are highly regarded by their leader, thus giving rise to safety norms (Mayer, Kuenzi, Greenbaum, Bardes, \& Salvador, 2009). Although no study, thus far, has investigated the effect of safetyspecific transformational leadership on norms for safety behaviors, extant literature suggests a positive relationship between transformational leadership and group norms (Ishikawa, 2012).

Through display of contingent reward and MEA behaviors, safety-specific transactional leaders remain vigilant of behavioral deviations in safety. These leaders further engage in exchange relationships with their subordinates, whereby they reward subordinates for meeting or exceeding safety goals, while punish them for failing to do so (Bass, 1999). By emphasizing contingent reward and reinforcing the importance of meeting safety goals consistently, these leaders establish shared norms of safety that encourage "efficient, systematic, and organized" behavioral regularities (Hofmann \& Jones, 2005, p. 511).

Unlike safety-specific transformational, contingent reward, and MEA leader behaviors, safety-specific MEP leader behaviors can negatively influence norms for safety behaviors. By allowing safety behaviors to drop below expected levels, these leaders "inadvertently 
communicate to subordinates that poor performance is anticipated but they are not expected to initiate action to correct it" (Masi \& Cooke, 2000, p. 24). Hence, rather than promoting norms for safety behaviors, these leaders enforce norms of "staying out of trouble" (Masi \& Cooke, 2000, p. 24). Literature exploring the link between safety-specific transactional leader behaviors and norms for safety behaviors is lacking. Additionally, no studies have explored the relationship between individual transactional leader behaviors and group norms in the workplace. However, one study reported a zero correlation between the three aggregated transactional leadership scales and empowerment norms (Masi \& Cooke, 2000).

Similar to MEP leaders, laissez-faire leaders are likely to negatively impact norms for safety behaviors. According to Hofmann and Jones (2005), due to the absence of clear direction, expectations, and rewards, such leadership "is likely to result in a situation that is much less consistent on a day-to-day basis" (p. 511). Since safety-specific laissez-faire leaders do not typically reinforce safety standards, it is likely for employees to perceive poor safety norms. These employees are inclined to take shortcuts to complete their tasks, and ignore safety policies and procedures. No studies have examined the relationship between laissez-faire leadership and norms in either the safety or non-safety context.

In the TPB framework, norms for safety behaviors are a proximal predictor of safety motivation (Ajzen, 1991). The strength of safety motivation to perform a behavior safely partly depends upon the strength of the norm for safety behaviors. According to Fogarty and Shaw (2010), employees who work together in an organization tend to consider themselves as belonging to specific workgroups. Group membership allows individuals' beliefs, feelings, and behaviors related to safety to be defined by the group prototype (Terry \& Hogg, 1996). Consequently, "group membership causes people to think, feel, behave, and define themselves in 
terms of group norms rather than unique properties to the self' (Terry \& Hogg, 1996, p. 779).

Stated differently, to maintain their group membership, employees are motivated to follow norms for safety behaviors followed by their workgroups. Empirical evidence supports the link between safety norms and safety motivation. In a study of maintenance personnel, safety norms were found to be negatively related to the intention to violate safety procedures (Fogarty \& Shaw, 2010). Another study provided evidence for the role of safe lifting norms in positively predicting intentions to lift safely in a sample of manufacturing employees (Johnson \& Hall, 2005).

Since leaders have been often credited with shaping norms for safety behaviors (Tucker, Chmiel, Turner, Hershcovis, \& Stride, 2008), leaders can create such norms which will further motivate employees to work in a safe manner. Although the efficacy of norms as an intervening process utilizing the FRL remains largely untested, one study found support for group norms as a mechanism between management attitude and safety violations (Fogarty \& Shaw, 2010). Noting the presence of clear theoretical bases and limited empirical evidence, the following hypotheses are proposed:

Hypothesis 3a: Safety-specific transformational leadership will exhibit an indirect positive effect on employee safety motivation through employee norms for safety behaviors.

Hypothesis 3b: Safety-specific contingent reward leadership will exhibit an indirect positive effect on employee safety motivation through employee norms for safety behaviors. 
Hypothesis 3c: Safety-specific management-by-exception active leadership will exhibit an indirect positive effect on employee safety motivation through employee norms for safety behaviors.

Hypothesis 3d: Safety-specific management-by-exception passive leadership will exhibit an indirect negative effect on employee safety motivation through employee norms for safety behaviors.

Hypothesis 3e: Safety-specific laissez-faire leadership will exhibit an indirect negative effect on employee safety motivation through employee norms for safety behaviors.

Perceived control over safety behaviors as a mediator. Research on behavioral control has garnered much attention in the past few decades. According to Thompson and Prottas (2005), "perceived [safety] control may be an important mechanism for influencing the relationship between organizational strategies and employee health and well-being" (p. 101). In fact, metaanalytic evidence has reported corrected correlations of .62 and .38 of behavioral control with intentions for safety behaviors and safety behavior, respectively (Hagger \& Chatzisarantis, 2009). More recently, research has documented that strong perceptions of safety control were associated with increased safety behaviors (Snyder, Krauss, Chen, Finlinson, \& Huang, 2011) and reduced injuries (Huang et al., 2004).

Perceptions of control over safety behaviors can be constructed in a number of ways. A finding from Batt and Valcour's (2003) study suggests that decision-making autonomy enhances the perception of control. Additionally, it has been proposed that supervisors can influence perceptions of control over safety behaviors (Greenberger \& Strasser, 1986). This is due to the fact that "supervisors have the authority to evaluate subordinates' job performance, their 
evaluations or sanctions directly influence subordinates' sense of control" (Yoon, Han, \& Seo, 1996, p. 691).

By empowering their employees to perform their jobs safely, safety-specific transformational leaders can reinforce perceptions of safety control (Yoon, et al., 1996). Empowered employees can "participate in devising and implementing constructive responses to [safety] problems and opportunities...[while] contributing to organizational effectiveness" (Graham, 1988, p. 78). Also, by demonstrating concern for employees' well-being and suggesting ways in which injuries can be avoided, safety-specific transformational leaders can instill perceptions of control over safety behaviors in their employees (Snyder et al., 2011). Last, but not least, these leaders boost employees' self-efficacy by convincing them of their capabilities to achieve higher levels of safety (Barling et al., 2002). Transformational leader behaviors are likely to bolster beliefs in employees regarding their ability to perform their jobs in a safe manner, as well as the outcomes of safety behaviors. Although no research has explored the relationship between safety-specific transformational leadership and perceived control over safety behaviors, quantitative evidence has corroborated the role of leaders in enhancing employee perceptions of safety control. For instance, using a sample of shipping and transportation employees, a study indicated a positive relationship between supervisor safety support and employee safety control (Huang et al., 2004). Another study reported a positive correlation between management commitment to safety and safety control across four industries (Huang, Ho, Smith, \& Chen, 2006).

Safety-specific contingent reward and MEA leaders provide incentives for safety behaviors and negative feedback for deviations in safety behaviors (Bass, 1985). To ensure that employees perform their jobs in a safe manner, these leaders provide necessary safety-related 
information to employees to assist them in completing their jobs in a satisfactory manner (Bernhard \& O’Driscoll, 2011). According to Pierce, Kostova, and Dirks (2001), the more knowledge an individual has about a job, the stronger are his perceptions of ownership. Therefore, by imparting the required safety knowledge, these leaders establish perceptions of control over safety behaviors in their employees. While research examining the effects of safetyspecific contingent reward and MEA leadership on perceived control over safety behaviors is missing, scant research confirms a positive relationship between general contingent reward and MEA with psychological empowerment (Zhu, Sosik, Riggio, \& Yang, 2012).

Conversely, safety-specific MEP and laissez faire leadership are expected to exhibit a negative relationship with perceived control over safety behaviors. Unlike transformational and transactional leaders, MEP and laissez-faire leaders neither actively monitor safety behaviors, nor devote time to safety training or development of employees (Bernhard \& O'Driscoll, 2011). As a result, employees of such leaders reduce their involvement in safety-related behaviors, thereby negatively impacting their perceptions of safety control (Pierce et al., 2001). Research in occupational safety is yet to examine the relationship of safety-specific MEP and laissez-faire leadership with perceived control over safety behaviors. However, Bernhard and O'Driscoll reported a negative correlation between general laissez-faire leadership and employee perceptions of ownership.

In the context of safety, TPB asserts that perceived control over safety behaviors is a direct determinant of safety motivation (Ajzen, 1991). According to TPB, an individual should have the required opportunities and resources in order to be motivated to perform the behavior. Employees "who believe that they have neither the resources nor the opportunities to perform a certain behavior are unlikely to form strong behavioral intentions to engage in it" (Ajzen \& 
Madden, 1986, p. 458). Hence, theoretically speaking, perceptions of control over safety behaviors should predict employee safety motivation. In fact, Fogarty and Shaw (2010) have partially tested this prediction. Specifically, they explored the impact of employees' perceptions of workplace pressures on intention to violate and found a positive relationship between the two variables.

Perceived control over safety behaviors may be a mediating mechanism through which leaders may impact safety motivation of employees. As previously mentioned, empirical research has found support for the notion that leaders provide control to their employees (Huang et al., 2004). In fact, Fogarty and Shaw (2010) found support for the link between work pressures (a control variable) and management attitudes and violation intentions. Given the above, the following hypotheses were proposed:

Hypothesis 4a: Safety-specific transformational leadership will exhibit an indirect positive effect on employee safety motivation through employee perceived control over safety behaviors.

Hypothesis $4 b$ : Safety-specific contingent reward leadership will exhibit an indirect positive effect on employee safety motivation through employee perceived control over safety behaviors.

Hypothesis 4c: Safety-specific management-by-exception active leadership will exhibit an indirect positive effect on employee safety motivation through employee perceived control over safety behaviors.

Hypothesis $4 d$ : Safety-specific management-by-exception passive leadership will exhibit an indirect negative effect on employee safety motivation through employee perceived control over safety behaviors. 
Hypothesis 4e: Safety-specific laissez-faire leadership will exhibit an indirect negative effect on employee safety motivation through employee perceived control over safety behaviors. 


\section{CHAPTER III}

\section{METHOD}

\section{Participants and Procedure}

The sample used in this study comprised of 168 working adults located within the U.S., who responded to surveys at Time 1 and Time 2. On average, the age of participants was 34.58 $(S D=10.36)$ years, and worked 43.58 hours $(S D=8.42)$ per week. Approximately, $68.0 \%$ of participants were male. The ethnic composition of participants was $76.2 \%$ Caucasian, $9.5 \%$ Black or African American, 6.0\% Hispanic or Latino, 4.2\% Asian, 3.6\% two or more ethnicities, and $0.6 \%$ American Indian and Alaska Native. Participants were employed in a wide range of industries, which comprised of retail and wholesale trade, healthcare, manufacturing, and construction, among others. In addition, all participants held high-risk jobs, such as policing, nursing, cashiering, and bartending. The mean duration for which participants were employed at their current organization and worked with their current supervisor were $4.92(S D=3.48)$ years and 7.23 $(S D=5.28)$ years, respectively. Sample characteristics are provided in Table 1.

To identify the participant pool for the current study, a demographic survey was posted on Amazon's Mechanical Turk (MTurk). A crowdsourcing website, MTurk "has great potential for organizational research" (Landers \& Behrend, 2015, p. 11). In recent years, MTurk has become a popular tool for psychological research (Paolacci \& Chandler, 2014). Evidence suggests that not only are the responses provided by participants recruited in-person versus those recruited through MTurk indistinguishable, but also are significantly more diverse with respect to ethnicity and socio-economic status (Casler, Bickel, \& Hackett, 2013). Researchers argue that Mturk provides access to employees that work across multiple organizations, which would otherwise be costly and time-consuming (Smith, Sabat, Martinez, Weaver, \& Xu, 2015). 
Table 1

Demographic and background characteristics of the overall sample

\begin{tabular}{lcc}
\hline Variable & Frequency & Percent \\
\hline Gender & & \\
Male & 114 & $67.90 \%$ \\
Female & 54 & $32.10 \%$ \\
& & \\
Ethnicity & & \\
Caucasian & 128 & $76.20 \%$ \\
Black or African American & 16 & $9.50 \%$ \\
Hispanic or Latino & 9 & $5.40 \%$ \\
Asian & 7 & $4.20 \%$ \\
Two or more races & 6 & $3.60 \%$ \\
American Indian and Alaska Native & 2 & $1.20 \%$
\end{tabular}

Hours employed per week

$\begin{array}{lcc}30-39 \text { hours } & 47 & 28.00 \% \\ 40+\text { hours } & 121 & 72.00 \%\end{array}$

Industry

Healthcare 39

Manufacturing 31

Other 20

Construction

$15 \quad 8.90 \%$

Accommodation and food services

$14 \quad 8.30 \%$

Transportation and warehousing

$14 \quad 8.30 \%$

Retail trade

$14 \quad 8.30 \%$

Agriculture

$5 \quad 3.00 \%$

Automotive repair, services, and parking

$4 \quad 2.40 \%$

Mining, quarrying and oil and gas

extraction

Fishing and forestry

Social Assistance

Utilities

$3 \quad 1.80 \%$

Professional and business services

$3 \quad 1.80 \%$

Sanitary services

$2 \quad 1.20 \%$

$2 \quad 1.20 \%$

$1 \quad 0.60 \%$

$1 \quad 0.60 \%$

Instructions for the demographic survey encouraged MTurk members who were

employed in an occupation where safety is of concern to participate in the study (see Appendix 
A). Members who completed the demographic survey were asked to indicate 1) the industry in which they worked, 2) their occupation, 3) the number of hours they worked per week, and 4) whether they reported to a direct supervisor or manager. Consistent with previous research (Paolacci, Chandler, \& Ipeirotis, 2010), participants were paid \$0.10 for completing the demographic questionnaire. Qualification of MTurk members was determined based on whether they 1) were employed in one of the high-risk industries, 2) worked in an occupation that is considered high-risk, 3) worked at least 30 hours a week, and 4) directly reported to a manager or supervisor. Determination for high-risk industries and occupations was made based on the fatal occupational injuries report by Bureau of Labor Statistics ([BLS], 2013a).

A total of 1,484 participants responded to the demographic survey. Majority of the participants worked for 40 or more hours $(60.0 \%)$, followed by those who worked between 30 to 39 hours $(18.1 \%), 20$ to 29 hours $(13.8 \%), 10$ to 19 hours $(6.3 \%)$, and one to nineteen hours (1.8\%). The ethnic composition was Caucasian (75.5\%), Asian (8.2\%), Black or African American (5.9\%), Hispanic or Latino (5.8\%), two or more ethnicities (3.4\%), American Indian and Alaska Native (0.7\%), and Native Hawaiian and Other Pacific Islander (0.1\%). Approximately $0.3 \%$ participants were unsure of their ethnicity.

Out of the 1,484 members who completed the demographic survey, 416 (28.0\% response rate) members qualified to participate in the study. These members were emailed through MTurk and were invited to complete the survey at Time 1 . In addition to the items assessing study variables, the survey consisted of four attention checks, which are highly recommended for Mturk samples for enhancing statistical power and reducing Type II errors (Goodman, Cryder, \& Cheema, 2013). To pass attention checks, participants were required to select the response option indicated by the item. For instance, a sample attention check item included in the survey was 
"Please select 'Always' for this item." Up to three reminder emails were sent to participants to enhance response rates.

Participants were paid $\$ 0.75$ to complete a 10-minute survey, which has been deemed a reasonable amount for a study of this duration (Barger, Behrend, Sharek, \& Sinar, 2011). A total of 416 participants were emailed the link for Survey 1, of which 285 responded, resulting in a response rate of $68.5 \%$. Of these 285 participants, eight participants did not pass any attention checks, 14 participants passed one attention check, 12 participants passed two attention checks, 22 participants passed three attention checks, and 229 participants passed all attention checks. To enhance the sample size for the present study, participants passed at least three (out of four) attention checks (i.e., 251) were considered for inclusion in the study, resulting in a response rate of $88.1 \%$. Specifically, 141 participants responded to the survey within a day of receiving the email. Of these, $128(90.8 \%)$ participants passed three or more attention checks. An additional 51 participants responded to the survey after receiving a reminder email two days later, of which 46 (90.2\%) participants passed at least three attention checks. A second reminder email was sent out three days after the first reminder. Seventy-two participants completed the survey upon receiving the second reminder, of which $61(84.7 \%)$ passed three or more attention checks. Participants that did not complete the survey even after receiving the second reminder were reminded a third time five days post the first reminder. A total of 21 participants completed the survey upon receiving the third reminder, of which $16(76.2 \%)$ passed three or more attention checks.

In order to investigate whether participants who completed survey at Time 1 differed from those who did not complete the Time 1 survey on any demographic and background characteristics, independent-samples $t$-test and chi-square tests were performed. Results indicated that participants who completed the survey $(M=32.87, S D=9.52)$ were older 
compared to those who qualified but did not complete the survey $(M=30.29, S D=7.76)$ at Time $1, t(305)=2.93, p=.004$. No significant differences were found across the two groups for gender (i.e., males vs. females, $\chi^{2}(1)=0.01, n s$ ), ethnicity (i.e., Caucasian vs. Non-Caucasian, $\left.\chi^{2}(1)=2.06, n s\right)$, or number of hours worked per week (i.e., $30-39$ vs. 40 hours or more, $\chi^{2}(1)=$ $0.00, n s)$.

Participants from Time 1 that passed at least three quality checks were sent another survey after three months (Time 2) from completing the first survey. Although the occupational safety literature does not provide optimal time intervals for detecting significant effects of leadership on employee safety motivation, researchers have suggested utilizing smaller intervals, such as 3 months, to find stronger relationships between leader behaviors and employee outcomes (e.g., Mullen \& Kelloway, 2009; Sims \& Szilagyi, 1979). To encourage participants to retake the survey at Time 2 , they were paid $\$ 1.20$ for completing the second survey. In addition to completing the measures, participants were asked to provide their MTurk Worker ID, as well as demographic information during each survey administration. Collecting demographic information during both survey administrations was deemed necessary to ensure that participants met the criteria needed to participate throughout the study. MTurk Worker ID served as an identifier to link surveys anonymously between Time 1 and Time 2 .

Of the 251 participants at Time 1, $168(66.9 \%)$ completed the survey at Time 2. Ninetyeight (58.3\%) participants completed the survey within a day of receiving the email, and passed three or more attention checks. Another 44 (26.2\%) participants completed the survey upon receiving the first reminder two days after the initial survey, and passed three or more attention checks. A total of $26(15.5 \%)$ participants responded to the second reminder, which was sent three days post the first reminder, and passed three or more attention checks. 
Once again, differences between participants who completed the survey at both Time 1 and Time 2 compared to those who completed the survey only at Time 1 were examined. Results indicated that participants who completed both surveys were older $(M=34.57, S D=10.40)$ than those who completed only Time 1 survey $(M=30.52, S D=7.73), t(237)=3.58, p<.001$. With respect to work hours, there were no differences between participants who completed the survey at both Time 1 and Time $2(M=42.58, S D=8.42)$ and those who completed the survey at only Time $1(M=43.16, S D=12.15), t(142)=-.412, n s$. Lastly, chi-square tests revealed that while there were significant differences in gender distribution $\left(\chi^{2}(1)=4.46, p=.035\right)$, the differences were non-significant for ethnicity (i.e., Caucasian vs. Non-Caucasian), $\chi^{2}(1)=1.67, n s$ ) between participants who completed the survey at both Time 1 and Time 2 and those who only completed it at Time 1. All participants who completed the survey at Time 2 passed three or more attention checks.

A priori power analyses were conducted for determination of appropriate sample size to test a latent structural equation model (SEM). As per Hu and Bentler's (1999) recommendations, fit values of .95 for CFI and .05 for RMSEA were used for the purposes of determining sample size. SPSS syntax was developed for CFI using Kim's (2005) equation, while generated for RMSEA using Timo Gnambs' website (n.d.). SPSS syntax for determining sample size for CFI and RMSEA is presented in Appendix B. Based on the power analyses, sample sizes required for CFI and RMSEA were estimated at 272 and 32, respectively. Hence, consistent with previous research (Atlantis, Chow, Kirby, \& Singh, 2006; Duffy, Ronis, Waltje, \& Choi, 2013), a more conservative sample size of 272 was originally sought for this study.

\section{Measures}


The sections below describe the measures used in the current study. Their full content is included in Appendix C. Safety-specific leadership, attitudes toward safety behaviors, norms for safety behaviors, and perceived control over safety behaviors were measured at Time 1, whereas safety motivation was assessed at Time 2 , three months later.

Safety-specific leadership. A total of 22 items assessing safety-specific leadership were administered. These items were adapted or taken from previous research (Podsakoff, MacKenzie, Moorman, \& Fetter, 1990; Bass \& Avolio, 1997; Avolio, Bass, \& Jung, 1999; Barling et al., 2002). All items were measured on a 5 -point Likert scale $(1=$ "Not at all" to $5=$ "Frequently or always").

Safety-specific transformational leadership. Eight items from by Barling et al. (2002) were used to assess safety-specific transformational leader behaviors. These items assessed all four dimensions of safety-specific transformational leadership (i.e., idealized influence, inspirational motivation, individualized consideration, and intellectual stimulation) - two items per dimension. Sample items included "My supervisor talks about his/her values and beliefs of the importance of safety" (idealized influence), "My supervisor provides continuous encouragement to do our jobs safely" (inspirational motivation), "My supervisor spends time showing me the safest way to do things at work" (individualized consideration), and "My supervisor suggests new ways of doing our jobs more safely" (intellectual stimulation). Cronbach's alpha reliability for this measure was .93 .

Safety-specific contingent reward leadership. Four items were used to assess safetyspecific contingent reward leader behaviors. Three items for this scale were adapted from The Multifactor Leadership Questionnaire (MLQ; Bass \& Avolio, 1997). In addition, one item was adapted from Podsakoff et al.'s (1990) leadership scale. A sample item was "My supervisor 
makes clear what one can expect to receive when safety goals are achieved." Cronbach's alpha coefficient for this scale was .87 .

Safety-specific management-by-exception active leadership. Four items from the MLQ (Bass \& Avolio, 1997) were adapted to assess safety-specific MEA leader behaviors. A sample item was "My supervisor keeps track of all safety mistakes." Cronbach's alpha reliability for this measure was .89 .

Safety-specific management-by-exception passive leadership. Two items from Barling et al. (2002) were utilized to assess safety-specific MEP leader behaviors. A sample item was "My supervisor waits for things to go wrong before taking action." Cronbach's alpha coefficient for the two items was .86 .

Safety-specific laissez-faire leadership. Four items were used to assess safety-specific laissez-faire leader behaviors. Two items were adapted from the MLQ (Form 5X; Avolio et al., 1999) measure, while two items were taken from Barling et al.'s (2002) scale. A sample item was "My supervisor avoids making decisions that affect safety on the job." Cronbach's alpha reliability for this measure was .90 .

To ascertain discriminant validity of the five leadership measures, the fit of a series of alternative models were examined using confirmatory factor analysis (CFA). In light of the recommendation to examine the factor structure of the full-range leadership model as it may be impacted by context (Antonakis et al., 2003), the fit of four different CFA models was compared. First, the fit of a five-factor model was tested where all leadership items loaded on their respective five factors. This model fit was then compared to a four-factor model fit, in which transformational leadership and contingent reward loaded on one factor, consistent with research showing that transformational leadership and contingent reward display similar 
relationships with various outcomes (Vandenberghe et al., 2002) and are highly correlated (Avolio et al., 1999). The four-factor model was further compared to a two-factor model which distinguished between positive (transformational, contingent reward, and MEA) and negative (MEP and laissez-faire) leader behaviors (Kelloway, Sivanathan, Francis, \& Barling, 2005). Lastly, the fit of a one-factor model was examined to assess whether all leadership items loaded on a single general leadership factor (Antonakis et al., 2003). Results indicated that the fivefactor model $\left(\chi^{2}(199)=442.71 p<.001 ; \mathrm{CFI}=.90, \mathrm{RMSEA}=.09,90 \% \mathrm{CI}[.08, .10]\right.$; SRMR $=$ $.05)$ provided the significantly better fit to the data compared to the four-factor model, $\chi^{2}(203)=$ $517.46, p<.001 ; \mathrm{CFI}=.88, \mathrm{RMSEA}=.10,90 \% \mathrm{CI}[.09, .11] ; \mathrm{SRMR}=.06\left(\Delta \chi^{2}(4)=58.47, p<\right.$ $.001)$, two-factor model, $\chi^{2}(208)=634.30, p<.001 ; \mathrm{CFI}=.83$, RMSEA $=.11,90 \% \mathrm{CI}[.10, .12]$; $\mathrm{SRMR}=.06\left(\Delta \chi^{2}(9)=144.25, p<.001\right)$, and one-factor model, $\chi^{2}(209)=1041.68, p<.001 ; \mathrm{CFI}$ $=.67, \mathrm{RMSEA}=.16,90 \% \mathrm{CI}[.15, .17] ; \mathrm{SRMR}=.11\left(\Delta \chi^{2}(10)=380.82, p<.001\right)$. All items obtained highly significant factor loadings on their respective latent factors in the five-factor model, with standardized factor loadings of .71 or higher.

Attitudes toward safety behaviors. Four items from Kelloway, Francis, Schat, and Iverson (2005) were used to assess attitudes toward safety behaviors. While the original measure consisted of eleven items, it suffers from scale contamination. Only four items in the scale pertain to attitudes toward safety behaviors. The remaining seven items refer to other safetyrelated constructs, such as safety compliance (e.g., "I always follow safe working procedures" and "I always try to follow safety regulations") and safety priority ("I have made safety a priority while at work"). Hence, the four items pertaining to safety attitudes were retained for the study. All items were measured on a 7-point Likert scale ( 1 = "Strongly disagree" to 7 = "Strongly agree"). The items were preceded by the stem "For me," which was followed by a statement, 
such as "For me, it is more important to work safely than it is to work quickly" and "For me, getting the job done is not as important as working safely." Cronbach's alpha coefficient for this scale was .83 .

Norms for safety behaviors. Although Fugas and colleagues (2011) have developed a scale for assessing safety norms, the measure does not assess norms for engaging in safety behaviors. Therefore, using Ajzen's (n.d.) recommendations, a six-item measure consistent with Theory of Planned Behavior (TPB; Ajzen, 1991) was developed to measure norms for safety behaviors. First, the behavior of interest (i.e., safety behavior) was specified. Next, safety behavior was defined as using safety equipment, following safety procedures, pursing safety standards, promoting safety within the workplace, and participating in voluntary activities related to workplace safety (Neal \& Griffin, 2006). Lastly, item stems provided by Ajzen were combined with examples of safety behaviors consistent with the definition. For instance, the item stem "Most co-workers whose opinions I value" was combined with the safety behavior "use the necessary safety equipment regularly," resulting in "Most co-workers whose opinions I value use the necessary safety equipment regularly.”

Two dimensions of norms were assessed: descriptive and injunctive norms (Fugas et al., 2011). All items were measured using a 7 -point Likert scale $(1=$ "Strongly disagree" to $7=$ "Strongly agree"). Each of the two dimensions were assessed by three items. Sample items included "Most co-workers whose opinions I value use the necessary safety equipment regularly" (descriptive norms) and "Most co-workers whose opinions I value approve of my using necessary safety equipment to do my job" (injunctive norms). Cronbach's alpha coefficient for the overall scale was .92 . 
Perceived control over safety behaviors. Four items from Snyder et al. (2011) were used to assess perceived control over safety behaviors. While the original measure consisted of seven items, six items focused on employee control over safety behaviors. However, two items from this measure loaded on a separate factor (i.e., "I have control over whether I use safety equipment" and "I have control over whether or not I engage in safe work behaviors"), and hence, were eliminated. An additional item was removed as it did not pertain to control over safety behaviors ("I am able to modify work conditions in order to make them safer"). The four items were measured on a 7-point Likert scale ( $1=$ "Strongly disagree" to 7 = "Strongly agree"). Sample items included "I am able to change unsafe practices at work" and "My job allows me to control whether I am safe at work." Cronbach's alpha reliability for this scale was .74.

To ensure that the measures of safety attitudes, safety norms, and perceived safety control represented distinct constructs, the fit of three competing models was examined with CFA. First, the fit of a four-factor model was assessed where items on safety attitudes, descriptive norms, injunctive norms, and perceived safety control loaded on four separate factors. Next, the fit of a three-factor model was tested where the items for each of the three mediators (i.e., safety attitudes, safety norms, and perceived safety control) loaded on their respective factors. Lastly, a one-factor model fit was examined where all three mediators loaded on a single factor. Analyses revealed that the four-factor model fit the data well $\left(\chi^{2}(71)=165.87, p<.001\right.$; CFI $=.90$, RMSEA $=.09,90 \%$ CI $[.07, .11]$; SRMR $=.06)$. Compared to the three-factor model $\left(\chi^{2}(74)=\right.$ $169.22, p<.001 ; \mathrm{CFI}=.90, \mathrm{RMSEA}=.09,90 \% \mathrm{CI}[.07, .11]$; SRMR $=.06)$, the four-factor model did not exhibit significantly better fit to the data $\left(\Delta \chi^{2}(3)=5.05, n s\right)$. The one-factor model demonstrated significantly poorer fit $\left(\chi^{2}(77)=379.90, p<.001 ; \mathrm{CFI}=.68, \mathrm{RMSEA}=.16,90 \%\right.$ CI $[.14, .17] ;$ SRMR $=.11)$ compared to the three-factor model $\left(\Delta \chi^{2}(3)=75.53, p<.001\right)$. 
Hence, a combined measure of norms for safety behaviors (descriptive and injunctive) was used in subsequent analyses for reasons of model parsimony. Standardized loadings for all items were significant and .35 or above.

Safety motivation. While a few measures of safety motivation exist in the literature, these usually assess safety attitudes rather than motivation (e.g., Dal Corso, 2008; Neal \& Griffin, 2006). Hence, employing recommendations by Ajzen (n.d.) described above, a six-item scale was developed for the purposes of the current study to measure safety motivation. All items were measured using a 7-point Likert scale ( $1=$ "Strongly disagree" to $7=$ "Strongly agree"). Sample items included "I plan to attend safety meetings even if they are not mandatory" and "I intend to follow all safety procedures even when I have deadlines to meet." Cronbach's alpha reliability for this scale was .86 .

To determine the factor structure of the safety motivation scale, a one factor CFA was performed. Results suggested acceptable fit to the data $\left(\chi^{2}(9)=14.18, n s ; \mathrm{CFI}=.98, \mathrm{RMSEA}=\right.$ $.06,90 \% \mathrm{CI}[.00, .12] ; \mathrm{SRMR}=.03)$. Also, the standardized loadings for all items were significant and exceeded .45 .

Control variables. Several variables were assessed to control for possible third variable effects. The rationale for including these variables, as well as descriptions of the measures are detailed below (Becker, 2005). Participants were asked to indicate their gender, age, ethnicity, hours worked per week, duration at current job, duration working with current supervisor, and tenure at current organization. Past research has revealed associations of these variables with occupational safety outcomes (Nahrgang, Morgeson, \& Hofmann, 2007; Hoffmeister et al., 2014). 
In addition, participants completed measures assessing conscientiousness and safety training. In the present study, conscientiousness was included as a potential control variable because it has shown significant correlations with safety motivation (Christian et al., 2009). Although safety training has not been linked to safety motivation directly, Burke et al. (2011) argued that through safety training, employees understood the risks associated with their jobs. Such realization might then motivate employees to perform their jobs in a safe manner. The measures for conscientiousness and safety training are described below:

Conscientiousness. Ten items from the International Personality Item Pool (Goldberg, 1992) were used to assess conscientiousness. All items were measured on a 5-point Likert scale ( 1 = "Strongly disagree" to $5=$ "Strongly agree"). Sample items included "I like order" and "I get chores done right away." This measure has shown acceptable internal consistency reliability of above .70, as well as satisfactory psychometric properties (Biderman \& Reddock, 2012; Sawhney \& Cigularov, 2014). Cronbach's alpha reliability for the conscientiousness scale in the present study was .88 .

Safety training. Two items were used to measure safety training: "How many hours of safety training have you completed in the last 6 months" and "Have you completed OSHA 10 and/or OSHA 30 certification?"

\section{Analyses}

Preliminary analyses. Prior to performing any analyses, data were examined for accuracy, missing data, non-normality, outliers, and linearity following recommendations by Tabachnick and Fidell (2013). Specifically, frequency tables were examined to determine whether item values fell within the range of their respective scales. Values were inspected to ensure that they were neither lower nor higher than the minimum or maximum integer values, 
respectively. To ensure normality of data, skewness and kurtosis of variables were assessed by comparing histograms of each item using SPSS 22.0 (IBM Corporation, 2011). Any standardized scores found to be more extreme than \pm 3.29 were considered outliers (Tabachnick \& Fidell, 2013). To overcome univariate non-normality, variables with outliers were transformed. Multivariate normality was assessed using Mahalanobis distance. Linearity of variables was examined through the inspection of scatterplots (Tabachnick \& Fidell, 2013).

Upon cleaning the data, assumption violations were examined for each variable. Specifically, assumptions of linearity and homoscedasticity were assessed. The assumption of linearity requires that the relationship between independent and dependent variables is linear. This assumption was examined for each variable using scatterplots, where the raw independent variable was plotted on the $\mathrm{x}$-axis and unstandardized residuals of the full regression model were plotted on the y-axis. Support for linearity was found if the Lowess line ran roughly straight (Cohen, Cohen, West, \& Aiken, 2003). The assumption of homoscedasticity requires that the variance of errors be constant regardless of the value of the independent variable (Cohen et al., 2003). An examination of scatterplots of predicted scores against residuals was performed to check for irregularities in the shape of the distribution of data. In the event of violation of homoscedasticity in a single independent variable, that independent variable was transformed. However, if this assumption was violated in multiple independent variables, all dependent variables were transformed. The type of transformation depended upon the degree to which data deviated from normality (Tabachnick \& Fidell, 2013). If the distribution deviated moderately from normality, a square root transformation was applied to the data. Similarly, in the case of substantial deviation, a log transformation was utilized. Lastly, if the distribution deviated severely from normality, an inverse transformation was applied. 
Hypotheses testing analyses. Main analyses were performed within an observed structural equation modeling (SEM) framework with robust maximum likelihood estimation (MLR) using Mplus 7.4. MLR yields less biased estimates when assumptions of multivariate normality are violated (Muthén \& Muthén, 1998-2015).

Prior to performing main analyses, scale scores were created for all nine variables (i.e., transformational leadership, contingent reward, MEA, MEP, laissez-faire leadership, attitudes toward safety behaviors, norms for safety behaviors, and perceived control over safety behaviors at Time 1 , and safety motivation at Time 2) by taking the average of the total items in each of the nine measures.

Since the hypothesized model did not meet the sample size requirements (i.e., five to 20 times the number of participants for each estimated path, Petraitis, Dunham, \& Niewiarowski, 1996), the overall model (see Figure 1) was broken down into five separate models by leadership behavior for purposes of simplification (see Figures 2, 3, 4, 5, and 6). First, a partially mediated model was tested for each of the five leadership dimensions. Specifically, safety motivation at Time 2 had a direct path from safety attitudes, safety norms, safety control, and safety leadership in addition to the control variables. At the same time, the three mediators (i.e., safety attitudes, safety norms, and safety control) were regressed on both the safety leadership dimension and control variables. Residuals of the mediators were allowed to covary. The partially mediated model was then compared to a fully mediated model in which a direct path from leadership to safety motivation was removed.

Before testing mediation hypotheses, model fit was examined for all structural models using chi-square (Jöreskog, 1969), comparative fit index (CFI; Bentler, 1990), root mean square error of approximation (RMSEA; Steiger, 1990), and root mean squared residual (SRMR; 
Bentler, 1995). The choice of the three fit indices was guided by simulation research suggesting that these indices are least sensitive to sample sizes (Fan, Thompson, \& Wang, 1999). Although the chi-square test has been traditionally used as an indicator of model fit (Ryan, Chan, Ployhart, \& Slade, 1999), it "provides a highly sensitive statistical test, but not a practical test, of model fit" (Cheung \& Rensvold, 2002, p. 234). Therefore, the statistic will be provided, but not interpreted with respect to model fit. CFI assesses model fit by comparing the model under investigation with the independence model while correcting for sample size (Bentler, 1990). Ranging from 0 to 1 , a CFI value of at least .90 is recommended, and a value greater than .95 is desired (Hu \& Bentler, 1999). The RMSEA assesses lack of fit between the model under investigation and an ideal model while taking errors of approximation into consideration (Browne \& Cudeck, 1993). RMSEA values between .06 and .08 indicate acceptable fit, while values of .05 and below indicate good fit (Hu \& Bentler, 1999). SRMR assesses model fit by examining the standardized difference between observed and predicted correlations. Values for SRMR ranging between .06 and .08 indicate acceptable fit, and values of .05 and below indicate good fit (Hu \& Bentler, 1999). Comparison of model fit between partially and fully mediated models was compared using a chi-square difference test.

Mediation hypotheses (i.e., Hypotheses 2a-2e, 3a-3e, and 4a-4e) were tested using the bootstrap approach, which has been recommended for small to moderate samples (Shrout \& Bolger, 2002). Bootstrapping utilizes a resampling procedure whereby data are repeatedly sampled from a parent data, thus creating an empirically established sampling distribution (Nevitt \& Hancock, 2001). This approach provides confidence intervals for indirect effects around the estimated coefficient. A significant indirect effect can be assumed if the confidence interval does not contain zero (Preacher \& Hayes, 2008). Specifically, a bias-corrected bootstrap 
method with 10,000 replications (see Preacher \& Hayes, 2008), which has demonstrated the most statistical power in simulation studies compared to other resampling methods (MacKinnon, Lockwood, \& Williams, 2004), was utilized to examine indirect effects. 


\section{CHAPTER IV}

\section{RESULTS}

\section{Preliminary Results}

For the purposes of this study, data for leadership and mediator variables at Time 1 and safety motivation at Time 2 were utilized. These data were examined for accuracy, normality and outliers, and assumptions of multivariate analysis using SPSS 22.0 (IBM Corporation, 2011) before testing study hypotheses. Specifically, frequency tables were examined to determine whether item values fell within the range of their respective scales. Values were inspected to ensure that they were neither lower nor higher than the minimum or maximum integer values (Tabachnick \& Fidell, 2013). There were no missing data as this was a web-based study and participants had to complete the surveys in order to receive payment. Hence, analyses proceeded to examine normality and identify both univariate and multivariate outliers.

Normality and Outliers. To ensure normality of data, histograms were visually examined for each study variable. In addition, following recommendations of Tabachnick and Fidell (2013), significance of skewness and kurtosis of study variables were assessed. Skewness values ranged between -.05 and .91, while kurtosis values ranged between .03 and 1.00. With the exception of safety-specific laissez-faire leadership which exhibited slight skewness (i.e., .91), no variables departed significantly from normality.

Further, standardized z-scores were inspected to identify univariate outliers. Any standardized score found to be more extreme than \pm 3.29 standard deviations away from the mean was considered an outlier as it would appear beyond the $p=.001$ criterion (Tabachnick \& Fidell, 2013). No univariate outliners were identified in the dataset, including among safetyspecific laissez faire leadership scores. Regardless, a square-root transformation was applied to 
safety-specific laissez faire leadership scores due to a moderate deviation from normality (Tabachnick \& Fidell, 2013), which substantially reduced the skewness of safety-specific laissez-faire leadership scores from .91 to .57 .

Next, multivariate outliers were examined for all study variables using Mahalanobis distance (Cohen et al., 2003; Tabachnick \& Fidell, 2013). Leverage was examined by creating a dummy variable, which served as the outcome variable for this test. The dummy variable was then regressed on all study variables (Tabachnick \& Fidell, 2013). Any case greater than $\chi_{10}^{2}=$ $29.588, p<.001$ was deemed a multivariate outlier. No cases were identified as multivariate outliers. Next, studentized residual and studentized deleted residuals were checked to determine discrepancy among variables. Any value greater than $t(167)=3.70$ was considered an outlier. One case was identified as a multivariate outlier. Lastly, influence was examined using standardized DfFIT. Any values greater than 1 are deemed outliers for small to medium samples. Two cases were identified as multivariate outliers. To handle multivariate non-normality, MLR was used to test study hypotheses. Hence, the original sample size of 168 participants was retained for the subsequent analyses.

Linearity and Homoscedasticity. The assumption of linearity was assessed for all study variables using scatterplots. Results indicated that the Lowess line ran roughly straight for all variables, thereby supporting the linearity assumption for all variables (Cleveland, 1979).

Next, assumption of homoscedasticity was examined, which requires that the variance of errors be constant regardless of the value of the independent variable (Cohen et al., 2003). Bivariate scatterplots demonstrated that the data were evenly dispersed throughout the plot. To test homoscedasticity, scatterplots of residuals against independent variables were visually 
examined. In addition, Breusch and Pagan's (1979) significance test of homoscedasticity was utilized, which provided support for this assumption.

\section{Hypotheses-Testing Results}

Correlational results. Table 2 provides means, standard deviations, internal consistency reliabilities, and correlations for all variables. Reliabilities for the study variables ranged between .75 and .93, and were deemed acceptable (Nunnally \& Bernstein, 1994). Of the seven potential control variables, only age $(r=.29, p<.001)$ and conscientiousness $(r=.41, p<.001)$ were significantly related to safety motivation, and were therefore, included as control variables in all main analyses (Becker, 2005). Correlation coefficients indicated that three of the safety-specific leader behaviors were significantly related to safety motivation. In particular, safety-specific transformational $(r=.23, p=.003)$, contingent reward $(r=.24, p=.002)$, and MEA $(r=.28, p<$ .001) leader behaviors were positively correlated with safety motivation, thereby lending support to Hypotheses 1a, 1b, and 1c, respectively. No evidence was found for relationships of safetyspecific MEP $(r=-.07, n s)$ and laissez-faire $(r=-.14, n s)$ leader behaviors with safety motivation, and hence, Hypotheses $1 \mathrm{~d}$ and 1e were not supported. 
Table 2

Means, standard deviations, reliabilities, and correlations for study variables

\begin{tabular}{|c|c|c|c|c|c|c|c|c|c|c|c|c|c|c|}
\hline & & $M$ & $S D$ & 1 & 2 & 3 & 4 & 5 & 6 & 7 & 8 & 9 & 10 & 11 \\
\hline 1. & Age (T1) & 34.57 & 10.40 & - & & & & & & & & & & \\
\hline 2. & Conscientiousness (T1) & 3.92 & 0.69 & $.25^{* *}$ & $(.88)$ & & & & & & & & & \\
\hline 3. & Transformational (T1) & 3.15 & 0.93 & -.01 & $.24 * *$ & $(.93)$ & & & & & & & & \\
\hline 4. & Contingent reward (T1) & 2.90 & 1.09 & .01 & $.26 * *$ & $.75 * *$ & $(.88)$ & & & & & & & \\
\hline 5. & MEA (T1) & 3.12 & 1.14 & .04 & $.25^{* *}$ & $.77 * *$ & $.78 * *$ & $(.91)$ & & & & & & \\
\hline 6. & MEP (T1) & 2.40 & 1.19 & .02 & -.08 & $-.55 * *$ & $-.51 * *$ & $-.51 * *$ & $(.89)$ & & & & & \\
\hline 7. & Laissez-faire (T1) & 1.95 & 0.99 & -.09 & -.11 & $-.52 * *$ & $-.47 * *$ & $-.49 * *$ & $.78 * *$ & $(.92)$ & & & & \\
\hline 8. & Safety attitudes (T1) & 4.65 & 0.88 & $.29 * *$ & $.31 * *$ & $.29 * *$ & $.20 * *$ & $.23 * *$ & -.14 & $-.16^{*}$ & $(.78)$ & & & \\
\hline 9. & Safety norms (T1) & 4.88 & 0.75 & -.03 & $.36^{* *}$ & $.44 * *$ & $.44 * *$ & $.39 * *$ & $-.32 * *$ & $-.34 * *$ & $.49 * *$ & $(.93)$ & & \\
\hline 10. & Safety control (T1) & 4.28 & 0.88 & .06 & $.23 * *$ & $.43 * *$ & $.35^{* *}$ & $.38 * *$ & $-.42 * *$ & $-.44 * *$ & $.38 * *$ & $.48^{* *}$ & $(.75)$ & \\
\hline 11. & Safety motivation (T2) & 4.60 & 0.86 & $.29 * *$ & $.41 * *$ & $.23 * *$ & $.24 * *$ & $.28 * *$ & -.07 & -.14 & $.51 * *$ & $.44 * *$ & $.28 * *$ & $(.86)$ \\
\hline
\end{tabular}

Note. $N=168 . \mathrm{MEA}=$ management-by-exception active. $\mathrm{MEP}=$ management-by-exception passive. Cronbach's alphas are presented in parentheses along the diagonal. $* p<.05 . * * p<.01$. 
Structural models. Due to the small sample size, the hypothesized model was broken into five separate models by each leadership dimension. Standardized path coefficients for all structural models are displayed in Figures 2, 3, 4, 5, and 6. The observed effects of age and conscientiousness were controlled for in all subsequent analyses by regressing the two variables on safety attitudes, safety norms, safety control, and safety motivation.

Safety-specific transformational leadership. The structural equation modeling results indicated that the partially mediated saturated model fit the data perfectly for safety-specific transformational leadership. Since fully saturated models utilize all degrees of freedom, perfect model fit is achieved (Parker \& Griffin, 2002). Further examination of the path coefficients indicated that the direct effect between safety-specific transformational leadership and safety motivation was not significant $(\beta=-.05, n s)$, suggesting possibility of full mediation. The partially mediated model was then compared to a fully mediated model. Results indicated that the fully mediated model fit the data well, $\chi^{2}(1)=0.73, n s ; \mathrm{CFI}=1.00, \mathrm{RMSEA}=.00,90 \% \mathrm{CI}$ $[.00, .20] ;$ SRMR $=.01$, and did not differ significantly from the partially mediated model $\left(\Delta \chi^{2}(1)=0.73, n s\right)$. Therefore, path coefficients for the full mediation model were interpreted. Standardized path coefficients for the full mediation model are presented in Figure 2.

Safety-specific transformational leadership positively predicted attitudes toward safety behaviors $(\beta=.23, p=.001)$, norms for safety behaviors $(\beta=.39, p<.001)$, and perceived control over safety behaviors $(\beta=.21, p=.013)$. Safety motivation was further predicted by safety attitudes $(\beta=.26, p=.002)$ and safety norms $(\beta=.26, p=.002)$. Perceived control over safety behaviors $(\beta=-.02, n s)$ did not significantly predict safety motivation. Additionally, examination of indirect effects with bootstrapping revealed significant indirect effects through safety attitudes $(\beta=.06, p=.022)$ and safety norms $(\beta=.10, p=.003)$, suggesting that these 
variables mediated the relationship between safety-specific transformational leadership and safety motivation, thereby supporting Hypotheses $2 \mathrm{a}$ and $3 \mathrm{a}$. However, the indirect effect through perceived control over safety behaviors was not significant $(\beta=-.01, n s)$, revealing lack of support for Hypothesis 4a. Bootstrapped indirect effects and their associated $95 \%$ CIs for transformational leadership are displayed in Table 3.

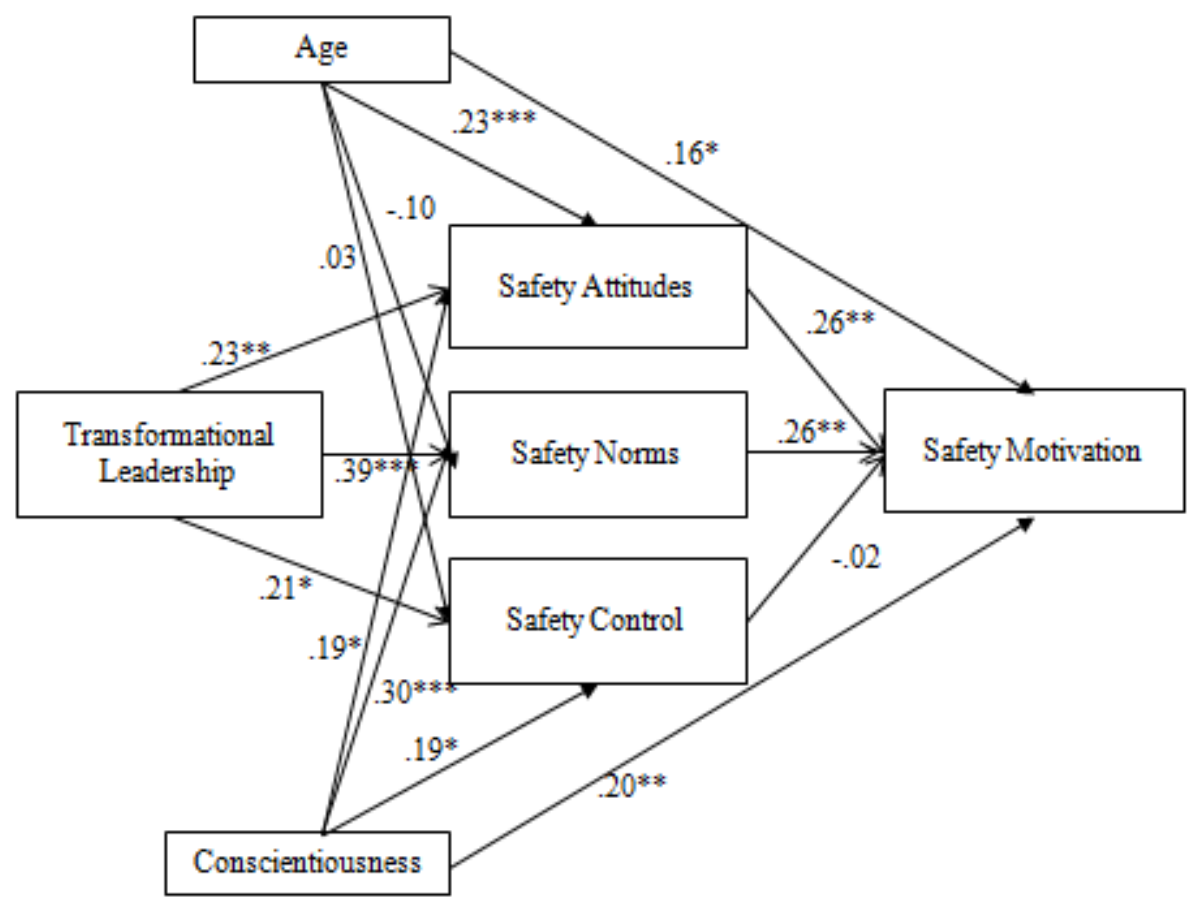

Figure 2. Summary of standardized path coefficients for safety-specific transformational leadership. Coefficients are provided for the full mediation model. $* p<.05 . * * p<.01 . * * * p<.001$

Safety-specific contingent reward leadership. The hypothesized partial mediation structural model for safety-specific contingent reward leadership was once again saturated, and revealed perfect fit to the data. Path coefficients indicated that the direct effect of contingent reward leadership on safety motivation was not significant $(\beta=-.00, n s)$. Hence, the partially mediated model was compared to a fully mediated model, which revealed good fit to the data, $\chi^{2}(1)=0.00, n s ; \mathrm{CFI}=1.00, \mathrm{RMSEA}=.00,90 \% \mathrm{CI}[.00, .00] ; \mathrm{SRMR}=.00$ and was not significantly different from the partially mediated model $\left(\Delta \chi^{2}(1)=0.00, n s\right)$. Therefore, path 
coefficients for the fully mediated model were interpreted. Standardized estimates for the full mediation model appear in Figure 3.

Safety-specific contingent reward leadership was a significant predictor of norms for safety behaviors $(\beta=.39, p<.001)$, and perceived control over safety behaviors $(\beta=.19, p=$ .021). However, contingent reward leadership did not significantly predict safety attitudes $(\beta=$ $.12, n s)$. In turn, safety attitudes $(\beta=.26, p=.002)$ and safety norms $(\beta=.26, p=.002)$

positively predicted safety motivation. However, control over safety behaviors $(\beta=-.02, n s)$ did not significantly predict safety motivation. Further examination of the bootstrapped indirect effects revealed that safety norms mediated the safety-specific contingent reward leadership and safety motivation relationship $(\beta=.10, p=.003)$, thus lending support to Hypothesis $3 \mathrm{~b}$. No mediation effect was found for safety attitudes $(\beta=.03, n s)$ and perceived control over safety $(\beta$ $=.00, n s)$, and hence, Hypotheses $2 \mathrm{~b}$ and $4 \mathrm{~b}$ were not supported. Bootstrapped estimates of indirect effects and their associated $95 \%$ CIs for contingent rewards are presented in Table 3.

Safety-specific management-by-exception active leadership. The hypothesized partially mediated model for safety-specific MEA leadership was saturated, and revealed perfect model fit. However, path coefficients indicated that the direct relationship between MEA leadership and safety motivation was not significant $(\beta=.06, n s)$. Hence, a fully mediated model was tested, which fit the data well, $\chi^{2}(1)=0.64, n s ; \mathrm{CFI}=1.00, \mathrm{RMSEA}=.00,90 \% \mathrm{CI}[.00, .19] ; \mathrm{SRMR}=$ .01 , and was not significantly different from the partially mediated model $\left(\Delta \chi^{2}(1)=0.64, n s\right)$. Therefore, path coefficients for the full mediation model were interpreted. Standardized path coefficients for the full mediation model are presented in Figure 4. 


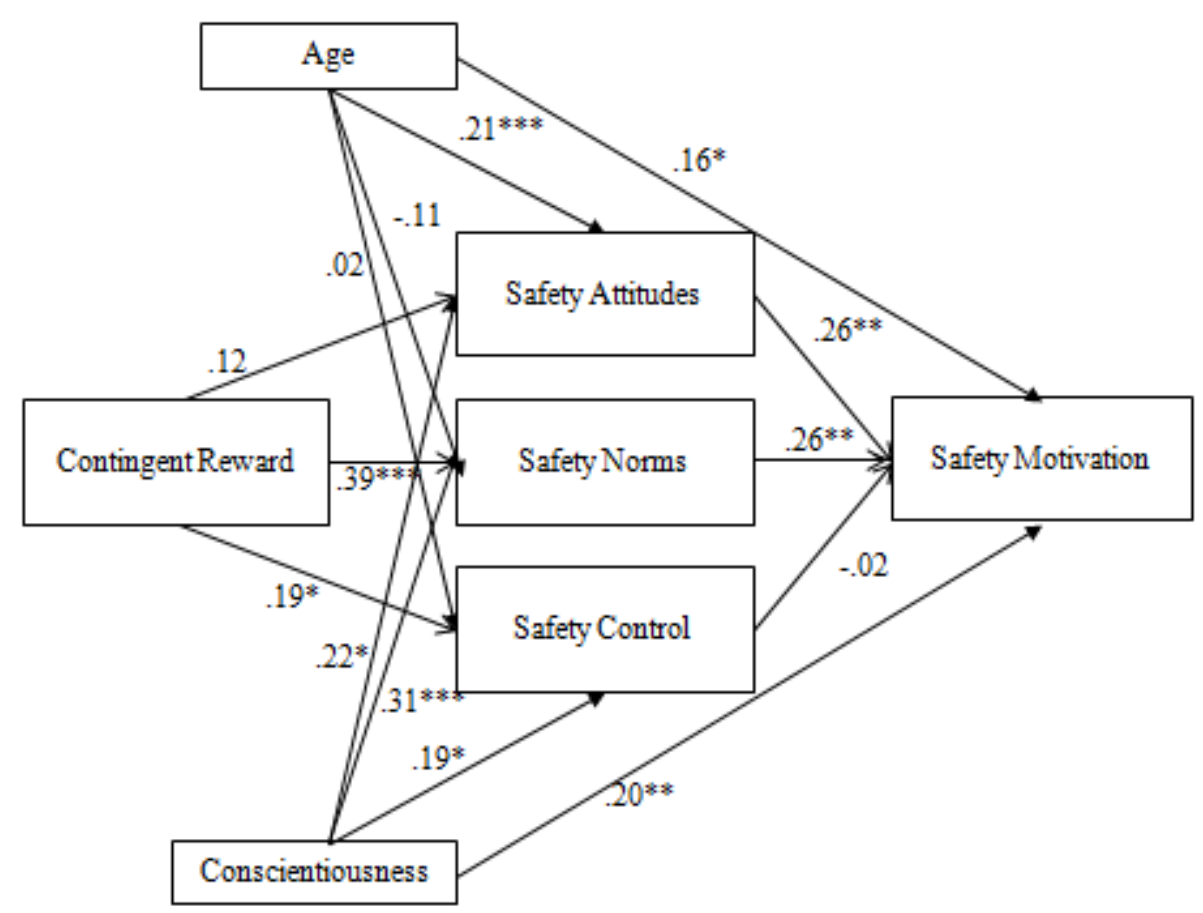

Figure 3. Summary of standardized path coefficients for safety-specific contingent reward leadership. Coefficients are provided for the full mediation model. $* p<.05 . * * p<.01 . * * * p<.001$.

Safety-specific MEA was a significant predictor of attitudes toward safety behaviors $(\beta=$ $.15, p=.037)$, norms for safety behaviors $(\beta=.34, p<.001)$, and perceived control over safety behaviors $(\beta=.20, p=.012)$. In turn, safety motivation was predicted by safety attitudes $(\beta=$ $.26, p=.002)$ and safety norms $(\beta=.26, p=.002)$, but not perceived control over safety $(\beta=-$ $.02, n s)$. As indicated in Table 3, results of the bootstrap test of indirect effects suggested that safety attitudes $(\beta=.04, p<.050)$ and safety norms $(\beta=.09, p=.009)$ mediated the relationship between safety-specific MEA and safety motivation, thereby supporting Hypotheses $2 \mathrm{c}$ and $3 \mathrm{c}$. Once again, perceived control over safety behaviors $(\beta=.00, n s)$ was not found to mediate the safety-specific MEA and safety motivation relationship, and hence, Hypothesis 4c was not supported. 


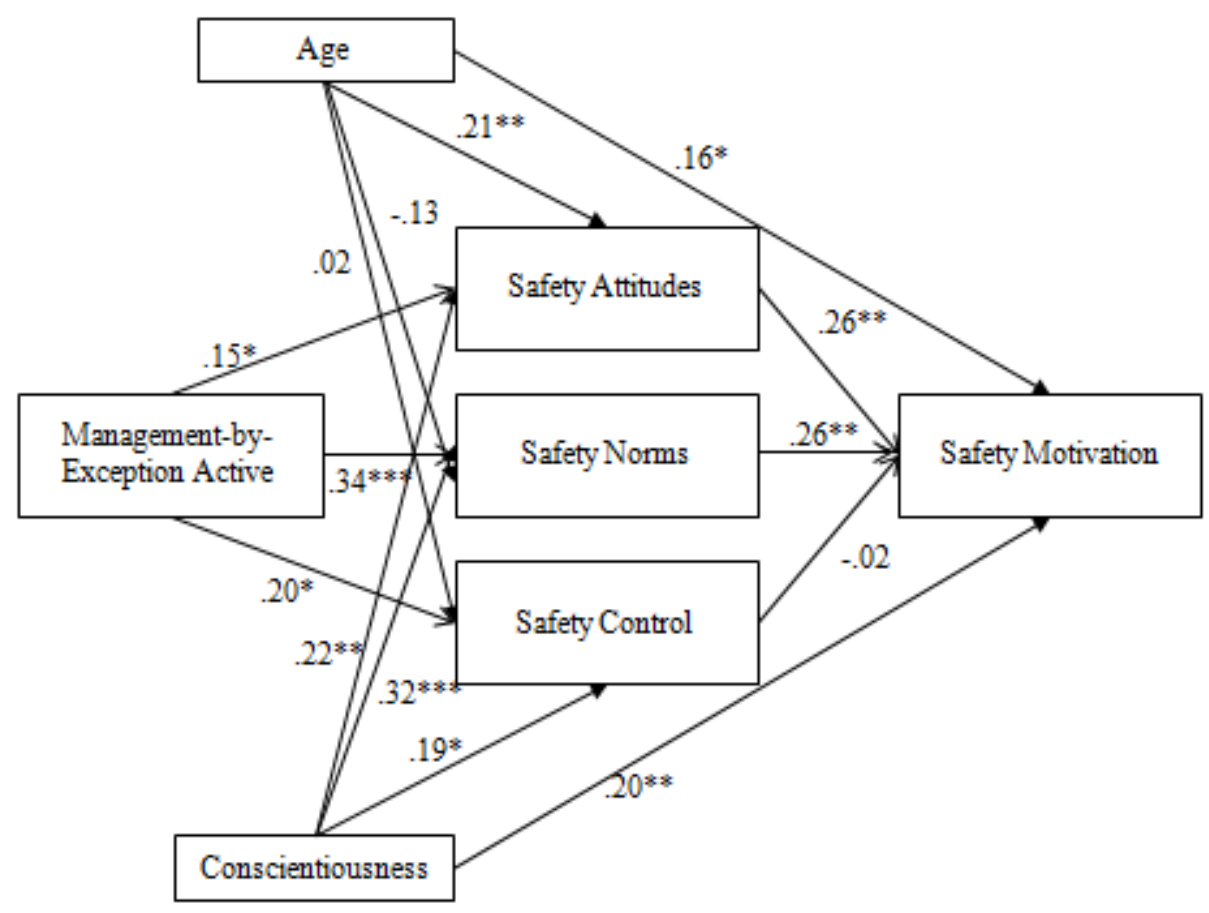

Figure 4. Summary of standardized path coefficients for safety-specific management-byexception active leadership. Coefficients are provided for the full mediation model. ${ }^{*} p<.05 . * * p<.01 . * * * p<.001$.

Safety-specific management-by-exception passive leadership. The partially mediated structural model for safety-specific MEP leadership demonstrated perfect fit to the data due to saturation. Since the direct relationship between MEP leadership and safety motivation was nonsignificant $(\beta=.07, n s)$ as indicated by the path coefficient, a fully mediated model was examined. The fully mediated model revealed good fit to the data, $\chi^{2}(1)=1.08, n s ; \mathrm{CFI}=1.00$, $\mathrm{RMSEA}=.02,90 \% \mathrm{CI}[.00, .21] ; \mathrm{SRMR}=.01$. This model was compared to a partially mediated model, which did not significantly differ from the full mediation model $\left(\Delta \chi^{2}(1)=1.08\right.$, $n s)$. Hence, path coefficients were once again interpreted for the fully mediated model. Standardized path coefficients for the fully mediated model are presented in Figure 5.

Safety-specific MEP negatively predicted safety norms $(\beta=-.21, p=.002)$ and perceived safety control $(\beta=-.24, p=.001)$, but not safety attitudes $(\beta=-.02, n s)$. In turn, safety 
motivation was predicted by safety attitudes $(\beta=.26, p=.002)$ and safety norms $(\beta=.26, p=$ $.002)$, but not perceived control over safety behaviors $(\beta=-.02, n s)$. Examination of indirect bootstrapped effects revealed that only safety norms demonstrated a mediating effect in the relationship between safety-specific MEP and safety motivation relationship $(\beta=.06, p=.019)$. Hence, Hypothesis $3 \mathrm{~d}$ was supported. However, neither safety attitudes $(\beta=.00, n s)$, nor safety control $(\beta=.00, n s)$ mediated the MEP - safety motivation relationship, thereby not lending support to Hypotheses $2 \mathrm{~d}$ and $4 \mathrm{~d}$. Bootstrapped indirect effects and their 95\% CIs for MEP are presented in Table 3 .

Safety-specific laissez-faire leadership. Lastly, the hypothesized partially mediated model for safety-specific laissez-faire leadership was once again saturated, and revealed perfect fit. However, the as indicated by path coefficients, relationship between laissez-faire leadership and safety motivation was non-significant $(\beta=.06, n s)$. Hence, a fully mediated model was tested, which indicated good fit to the data, $\chi^{2}(1)=0.77, n s ; \mathrm{CFI}=1.00, \mathrm{RMSEA}=.00,90 \% \mathrm{CI}[.00$, $.20] ;$ SRMR $=.01$. Compared to the fully mediated model, the partially mediated model did not provide substantially better fit, $\left(\Delta \chi^{2}(1)=0.77, n s\right)$. Therefore, path coefficients for the full mediation model were interpreted. Standardized path coefficients for the full mediation model can be found in Figure 6. 


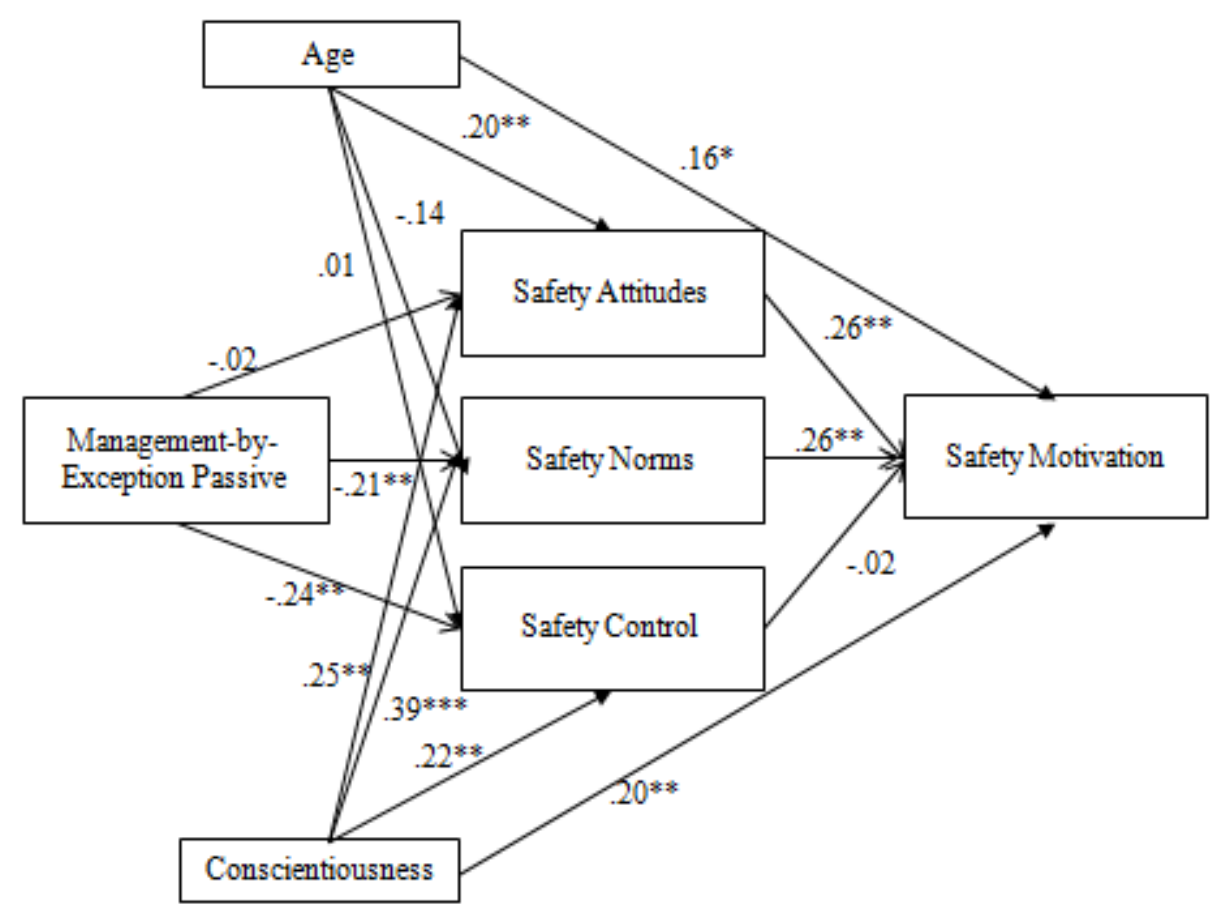

Figure 5. Summary of standardized path coefficients for safety-specific management-byexception passive leadership. Coefficients are provided for the full mediation model. $*_{p}<.05 . * *_{p}<.01$.

Safety-specific laissez-faire leadership negatively and significantly predicted norms for safety behaviors $(\beta=-.31, p<.001)$ and perceived control over safety behaviors $(\beta=-.28, p<$ $.001)$. However, these leader behaviors did not significantly predict safety attitudes $(\beta=-.08, n s)$. Safety motivation, in turn, was predicted by safety attitudes $(\beta=.26, p=.002)$ and safety norms $(\beta=.26, p=.002)$, but not safety control $(\beta=-.02, n s)$. As presented in Table 3 , indirect effects with bootstrapping revealed that safety norms mediated the relationship between laissez-faire leadership and safety motivation $(\beta=-.08, p=.005)$, thus lending support to Hypothesis 3e. Safety attitudes $(\beta=-.02, n s)$ and safety $\operatorname{control}(\beta=.01, n s)$ did not mediate the laissez-faire leadership - safety motivation relationship, and therefore, Hypotheses $2 \mathrm{e}$ and $4 \mathrm{e}$ were not supported. 


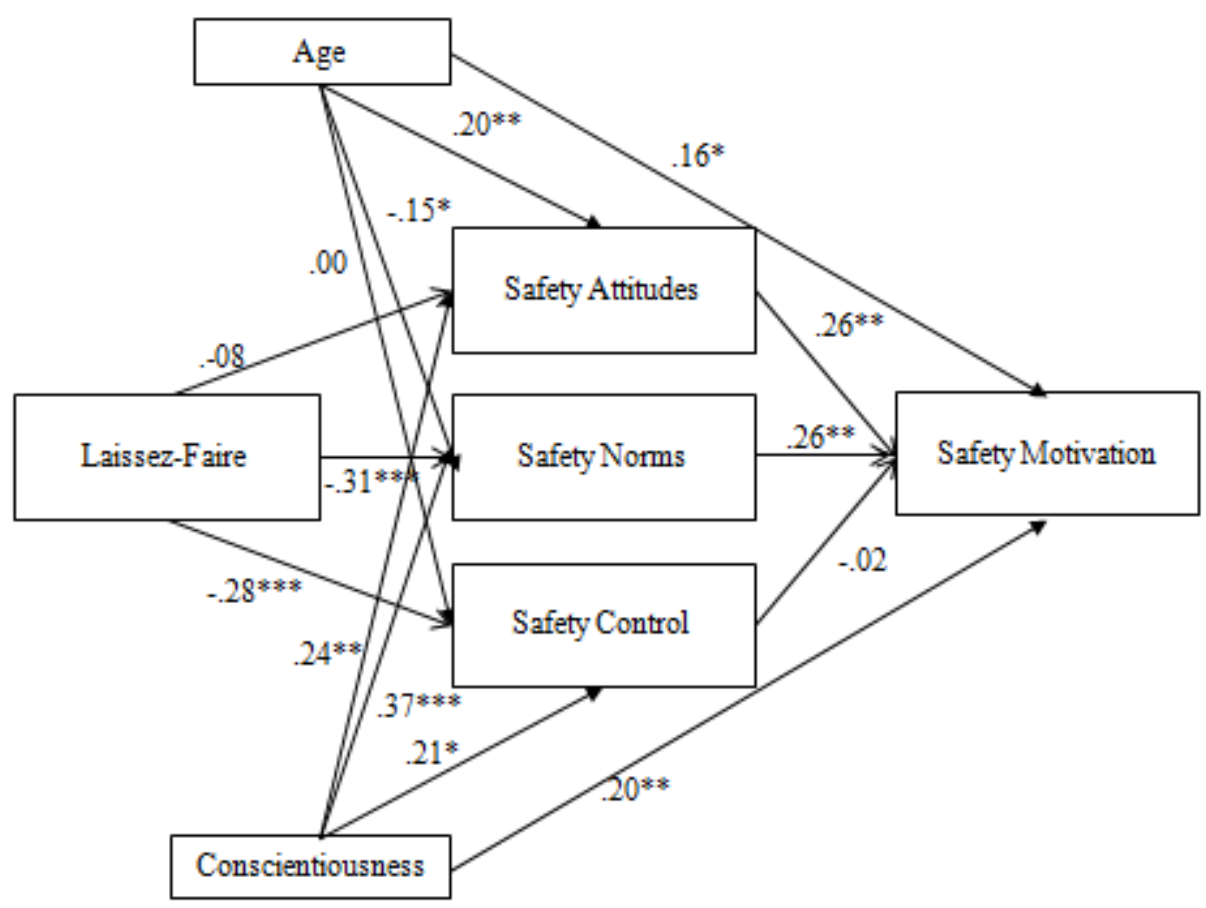

Figure 6. Summary of standardized path coefficients for safety-specific laissez-faire leadership. Coefficients are provided for the full mediation model. $* p<.05 . * * p<.01 . * * * p<.001$. 
Table 3

Standardized coefficients and bootstrap intervals for indirect effects

\begin{tabular}{|c|c|c|c|}
\hline \multirow[b]{2}{*}{ Model Pathways } & \multirow[b]{2}{*}{$\begin{array}{c}\text { Standardized } \\
\text { Coefficients }\end{array}$} & \multicolumn{2}{|c|}{ 95\% Confidence Interval } \\
\hline & & Lower & Upper \\
\hline Transformational $\rightarrow$ Safety attitudes $\rightarrow$ Safety motivation & .059 & .020 & .124 \\
\hline Transformational $\rightarrow$ Safety norms $\rightarrow$ Safety motivation & .102 & .043 & .179 \\
\hline Transformational $\rightarrow$ Safety control $\rightarrow$ Safety motivation & -.005 & -.051 & .023 \\
\hline Contingent reward $\rightarrow$ Safety attitudes $\rightarrow$ Safety motivation & .032 & -.003 & .096 \\
\hline Contingent reward $\rightarrow$ Safety norms $\rightarrow$ Safety motivation & .102 & .041 & .179 \\
\hline Contingent reward $\rightarrow$ Safety control $\rightarrow$ Safety motivation & -.004 & -.048 & .020 \\
\hline Management-by-exception active $\rightarrow$ Safety attitudes $\rightarrow$ Safety motivation & .040 & .004 & .104 \\
\hline Management-by-exception active $\rightarrow$ Safety norms $\rightarrow$ Safety motivation & .089 & .032 & .167 \\
\hline Management-by-exception active $\rightarrow$ Safety control $\rightarrow$ Safety motivation & -.004 & -.049 & .023 \\
\hline Management-by-exception passive $\rightarrow$ Safety attitudes $\rightarrow$ Safety motivation & -.004 & -.052 & .032 \\
\hline Management-by-exception passive $\rightarrow$ Safety norms $\rightarrow$ Safety motivation & -.056 & -.117 & -.019 \\
\hline Management-by-exception passive $\rightarrow$ Safety control $\rightarrow$ Safety motivation & .005 & -.028 & .051 \\
\hline Laissez-faire $\rightarrow$ Safety attitudes $\rightarrow$ Safety motivation & -.021 & -.073 & .011 \\
\hline Laissez-faire $\rightarrow$ Safety norms $\rightarrow$ Safety motivation & -.082 & -.149 & -.033 \\
\hline Laissez-faire $\rightarrow$ Safety control $\rightarrow$ Safety motivation & .006 & -.031 & .061 \\
\hline
\end{tabular}

Note. Standardized path coefficients provided are for full mediation models. 


\section{CHAPTER V}

\section{DISCUSSION}

This study extends previous research that has attempted to examine the processes through which organizational factors, such as safety climate and leadership, impact safety motivation (Fogarty \& Shaw, 2010; Lee et al., 2013). Although a few studies have investigated the relationship of safety-specific transformational (Conchie, 2013) and passive leader behaviors (Jiang \& Probst, 2016) on safety motivation, no study, thus far, has examined the influence of all safety-specific leader behaviors included in the Full-Range Leadership model (FRL; Bass, 1985) on safety motivation. Grounded in FRL and Theory of Planned Behavior (TPB; Ajzen, 1991), the current study examined the role of the full range of safety-specific leader behaviors, namely, transformational, contingent reward, management-by-exception active (MEA), management-byexception passive (MEP), and laissez-faire on employee safety motivation. In addition, the present study utilized a three month time-lagged study design to investigate three mechanisms (i.e., safety attitudes, safety norms, and perceived safety control) through which safety-specific leaders enhance motivation of employees to work in a safe manner. Overall, the findings of the current study provided support for the TPB in the context of safety. In the following sections, I discuss the findings relating to the study hypotheses, followed by theoretical and practical implications of these findings, strengths and limitations, and areas for future research.

In line with Hypotheses 1a, 1b, and 1c, safety-specific transformational, contingent reward, and MEA leadership positively predicted safety motivation of employees three months later. These findings are consistent with TPB, which stipulates that beliefs held by individuals about others' expectations of them with respect to engaging in certain behaviors have a strong impact on the individual's intentions to engage in that behavior (Ajzen, 1991). If employees of 
transformational leaders perceive that they are expected to perform their jobs safely, they are likely to be motivated to engage in safety behaviors. Similarly, in line with the FRL model, the results of this study indicate that by instilling confidence in their employees with respect to achieving safety goals, prioritizing employee safety, communicating high expectations with regards to safety, and pushing their employees to surpass minimum safety standards (Bass, 1985), safety-specific transformational leaders motivate employees to perform their jobs in a safe manner. The findings of this study are consistent with those reported by Conchie (2013), who found that safety-specific transformational leadership predicted intrinsic motivation in construction workers.

As expected, and in accordance with previous research (Judge \& Piccolo, 2004), this study found that safety-specific contingent reward behaviors displayed by leaders positively predicted safety motivation. By exhibiting safety-specific contingent reward behaviors where leaders provide incentives to subordinates for meeting safety standards, these leaders provide extrinsic motivation for safety behaviors. Similarly, by specifying appropriate safety behaviors, as well as monitoring employee behaviors for safety deviances, MEA leaders extrinsically motivate employees to perform their jobs safely.

Interestingly, Hypotheses 1d and 1e were not supported as MEP and laissez-faire leader behaviors did not exhibit significant relationships with safety motivation following three months. The non-significant findings can be explained by the passive nature of MEP and laissez-faire leader behaviors, due to which these leaders are unable to inspire or motivate their employees (Kelloway, Sivanathan, Francis, \& Barling, 2005). By ignoring safety concerns (Kelloway et al., 2006), these leaders may send a message to their subordinates that safety behaviors are neither important, nor expected of them. Due to the lack of normative beliefs regarding engaging in 
safety behaviors, the motivation of subordinates working for such a leader is unlikely to be impacted. In fact, consistent with the current study, previous research was unable to establish a significant link between laissez-faire leadership and safety perceptions (Nielsen, 2013).

With respect to the mediation hypotheses, results suggested that safety attitudes mediated the relationship between safety-specific leader behaviors and safety motivation for transformational and MEA leadership, thereby lending support to Hypotheses 2a and 2c. TPB suggests that attitudes are reflective of beliefs held by individuals about specific behaviors (Ajzen, 1991). In the context of safety, employee safety beliefs impact attitudes toward safety behaviors. Because attitudes formed via direct experience demonstrate more stability (Fazio \& Zanna, 1981), safety attitudes developed through observing one's leader may strongly impact safety motivation. Consistent with FRL model, transformational leaders strengthen beliefs among their employees regarding their ability to work safely, thereby promoting favorable attitudes toward safety behaviors. Additionally, by sending a message that safety is crucial for the welfare of employees, transformational leaders are likely to be perceived as trustworthy and committed to safety (Bommer et al., 2005). Lastly, these leaders are likely to evoke favorable attitudes toward safety by becoming role models for safety behaviors and providing individualized safety support. Similarly, safety-specific MEA leaders can construct attitudes for safety among their employees by clarifying their expectations regarding the desired behaviors (Podsakoff et al., 2006), and providing negative feedback and reinforcement when employees fail to comply with safety policies. These findings are particularly promising as previous research was unable to demonstrate a mediating role of safety attitudes in the transformational leadership - safety motivation relationship among foodservice workers (Lee et al., 2013). However, it is to be noted that Lee et al. examined perceptions of general leadership rather than 
safety-specific leader behaviors. In fact, extant research has determined that safety-specific leader behaviors account for additional variance in safety criteria, such as safety attitudes and intentions to promote safety compared to general leader behaviors (Mullen \& Kelloway, 2009).

Hypotheses 2b, 2d, and 2e were not supported as safety attitudes did not mediate the leadership - safety motivation link for contingent reward, MEP, and laissez-faire leadership. Findings indicated that contingent reward leadership did not predict employee safety attitudes. Participants in the current study belonged to a wide range of industries. Some industries represented in this study, such as healthcare, may have a climate for safety that is more salient than others. In such industries, rewards for safety performance may have negligible influence on attitudes toward safety behaviors. Future research should explore safety climate as a moderator in the relationship between contingent reward behaviors and safety attitudes to determine if contingent reward leadership has a differential effect on attitudes toward safety behaviors in industries with high and low safety climate.

Similarly, safety-specific MEP and laissez-faire leader behaviors did not demonstrate negative relationships with safety attitudes as hypothesized. In line with FRL model, MEP leaders intervene only when a problem arises, and laissez-faire leaders abdicate responsibility altogether. Due to their indifference towards safety, passive leaders are unlikely to dedicate time and resources to foster attitudes toward safety. Consistent with the findings of the present study, it has been argued that due to the passive approach used by these leaders, they "have little impact on group activities and achievements" (Nielsen, 2013, p. 129).

Results of the present study demonstrated support for Hypotheses 3a, 3b, 3c, 3d, and 3e. Specifically, safety norms mediated the leadership - safety motivation relationship for all five leadership dimensions. These results are consistent with the contention that leaders play a pivotal 
role in norm formation (Taggar \& Ellis, 2007). In line with the FRL model, transformational leaders can establish norms for safety behaviors by acting as role models for safety, thereby encouraging employees to emulate them. At the same time, by creating a sense of identity for the team, these leaders can gain the trust of their employees. According to social identity theory, when individuals consider themselves to be a part of a group, "they are motivated to identify and conform to shared group norms" (Haslam, Powell, \& Turner, 2000, p. 330). Therefore, employees who identify with work groups that have salient norms toward safety behaviors are likely to be motivated to conform to these safety norms. Similarly, by providing positive reinforcement for working safely and negative reinforcement for deviating from safety policies and procedures, leaders exhibiting contingent reward and MEA behaviors enforce safety norms where employees are rewarded for engaging in safety behaviors.

As expected, both MEP and laissez-faire leadership were negatively associated with norms for safety behaviors. TPB suggests that normative beliefs influence norms for performing a behavior (Ajzen, 1991). In line with the FRL model, MEP and laissez-faire leaders do not cultivate expectations regarding following safety standards. Therefore, they inadvertently set norms of unsafety within their teams where employees of such leaders are motivated to complete the job quickly rather than safely.

The current study did not find support for Hypotheses 4a, 4b, 4c, 4d, and 4e. Specifically, perceived control over safety behaviors did not mediate the leadership - safety motivation relationship for any of the five leadership dimensions. However, the findings indicated that active leadership positively predicted perceived control for safety behaviors while passive leader behaviors negatively impacted safety control. Ajzen (1991) has argued that the "importance of attitude, subjective norm, and perceived behavioral control in the prediction of intention is 
expected to vary across behaviors and situations" (p. 188). In other words, in the context where attitudes and norms have a strong impact on intention, the degree of control perceived may be less predictive of intention. In the current study, norms for safety behaviors predicted safety motivation for all leadership dimensions, while attitudes toward safety behaviors predicted safety motivation for transformational and MEA leadership.

Another explanation for these findings may be the lack of resources made available to the employees by their organizations. The degree of control provided to an employee depends on a number of factors, such as organizational hierarchies, regulations, standards, and rules that specify desirable behaviors (Das \& Teng, 2005). As proposed by the FRL model, safety-specific transformational, contingent reward, and MEA leaders can provide control to their employees by enhancing their self-efficacy and imparting relevant safety knowledge. Similarly, MEP and laissez-faire leaders can negatively impact perceptions of safety control by withholding information pertaining to safety. However, despite the control (or lack thereof) provided by leaders to engage in safety behaviors, employees may not have access to the additional resources that are provided by other organizational agents to execute safety behaviors. Hence, these lack of resources may explain the non-significant relationship between control over safety behaviors and safety motivation.

\section{Implications for Research and Practice}

The findings of the current study provide a more complete understanding of the processes that drive motivation to perform safely in high-risk industries. Specifically, this study utilizes TPB (Ajzen, 1991) to examine the relationship between safety-specific leadership and safety motivation. Extant models of safety performance (Christian et al., 2009; Neal et al., 2000) have proposed a direct link between leadership and safety motivation. While Fogarty and Shaw (2010) 
had explored mediators in the relationship between safety climate and intention to violate, this is the first study to have explored the impact of a range of active and passive leader behaviors on safety motivation through attitudes, norms, and control toward safety behaviors. The findings of this study indicate that existing models of safety should incorporate employee attitudes and norms toward safety behavior as drivers of safety motivation. In addition, this study augments support for the applicability of the TPB in the context of safety. While a few studies have employed this framework to examine safety attitudes, norms, and control as mechanisms (Johnson \& Hall, 2005; Lee et al., 2013), this is the first study to provide a glimpse of the impact of safety-specific leader behaviors, attitudes, norms, and control toward safety behaviors on safety motivation in a time-lagged design.

While several studies have recognized the positive impact of transformational and contingent reward leadership on safety outcomes (Clarke \& Ward, 2006; Kapp, 2012; Hoffmeister et al., 2014), few studies have examined MEA (Clarke, 2013) and passive leader behaviors (Kelloway et al., 2006). By investigating the processes through which both active and passive leader behaviors impact safety motivation, this research bolsters the contention that positive and proactive leader behaviors are beneficial for safety outcomes (Barling et al., 2002). At the same time, the study also highlights the insignificant role of MEP and laissez-faire leader behaviors in improving safety motivation. While passive leadership has received attention in the occupational safety literature (e.g., Kelloway et al., 2006), no study has explored the differences in processes through which passive leaders impact safety motivation. In fact, this is the first study to utilize TPB to understand the processes through which both active and passive leader behaviors impact safety motivation. 
The findings of this study indicated that the pattern of relationships exhibited by transformational and MEA leadership were similar. For instance, both transformational and MEA leadership were positively related to safety attitudes, norms, and control. In accordance with the FRL model (Bass, 1985), these findings suggest that transformational leaders can evoke favorable attitudes, norms, and control over safety behaviors through idealized influence, inspirational motivation, individualized consideration, and intellectual stimulation. MEA leaders can arouse positive safety attitudes, norms, and control by clarifying expectations regarding safety behaviors, and providing negative reinforcement to employees that fail to meet safety standards (Howell \& Avolio, 1993; Podsakoff et al., 2006). Similarly, in addition to exhibiting no relationship with safety attitudes, both MEP and laissez-faire leadership displayed comparable relationships with safety norms and control. As suggested by the FRL model, by failing to provide safety-specific training, passive leaders downplay the importance of safety behaviors, thereby cultivating unfavorable norms and perceptions of control related to safety (Bernhard \& O’Driscoll, 2011). Considering the indistinguishable findings across the active and passive leadership dimensions, it is possible that there may not be any underlying differences across these two groups of leadership behaviors when it comes to predicting safety attitudes, norms, control, and motivation.

The results of this study have significance for practitioners as well. Meta-analytic evidence has established the link between safety motivation and safety performance (Christian et al., 2009). By motivating employees to work in a safe manner, leaders can enhance employee safety performance. Specifically, by articulating a vision for safety and reinforcing value of safety, leaders can instill favorable attitudes toward safety, as well as bolster safety norms. Employees with positive safety attitudes and safety norms, in turn, are more likely to exhibit 
safety motivation, and work in a safe manner. Hence, organizations can improve safety performance and reduce accidents and injuries among employees by focusing on safety-specific leadership development. In fact, extant research has found that providing feedback to leaders regarding their safety-specific interactions with employees can increase employee safety performance (Zohar \& Luria, 2003).

It is to be noted that safety-specific contingent reward behaviors did not impact attitudes toward safety behaviors in the current study, but exhibited a positive relationship with safety motivation. An implication of this finding is that although contingent reward leaders may impact employee safety motivation, the results may be temporary. For instance, removal of these rewards could negatively impact employee safety motivation. While contingent reward behaviors may be important for safety motivation, organizations should not solely rely on rewards to motivate employees.

The non-significant findings of the current study related to safety control also have implications for organizations. The findings of this study suggest that while leader behaviors specified by the FRL model are positively or negatively related to safety control, perceptions of safety control do not predict safety motivation. It is possible that despite perceiving control over safety, employees may not be able to execute control over safety due to lack of resources. Organizations may consider providing necessary resources to enhance employee motivation.

\section{Strengths, Limitations, and Future Directions}

The present study makes several contributions to the occupational safety literature that must be highlighted. This is the first study to have utilized the FRL in its entirety to examine the role of safety-specific leadership on safety motivation. Previous research that explored the relationship between leadership and safety motivation relied solely on transformational (e.g., Lee 
et al., 2013) or MEP (Jiang \& Probst, 2016) leader behaviors. This study extends previous research by examining the effects of passive safety-specific leader behaviors (e.g., MEP and laissez-faire) in addition to active leader behaviors (i.e., transformational, contingent reward, and MEA).

Another contribution of this study is the utilization of TPB in the context of safety. Although TPB has often been used to predict a variety of motivations, such as intention for exercise (Norman, Conner, \& Bell, 2000), driving speed (Elliott, Armitage, \& Baughan, 2007), and using electronic recruitment services (Lin, 2010), few studies have utilized this theory for examining safety motivation of employees (Johnson \& Hall, 2005; Fogarty \& Shaw, 2010). While existing models of safety have established the link between leadership and safety motivation (Christian et al., 2009), this study incorporates TPB to shed light on the processes through which leaders can motivate safety performance of their subordinates.

The present study employed stringent controls to strengthen the confidence in the relationships found in this study. Inclusion of control variables "increases the probability that the reliability of the causal relationships found is high" (Barrow, 1976, p. 440). Therefore, by removing the influence of age and conscientiousness, this study minimized potential biases (Locke \& Latham, 2009).

A particular strength of the current study is that participants were employed in a variety of industries, such as construction, manufacturing, and healthcare, among others. Additionally, all participants were employed in high-risk occupations, such as policing, nursing, and bartending. Due to the diversity of the sample, the findings of this study should generalize to workers in high-risk occupations across the U.S. Since majority of extant research on occupational safety is conducted within a single organization, and is industry-specific (DeJoy, 
Schaffer, Wilson, Vandenberg, \& Butts, 2004; Mark et al., 2007; Kath, Marks, \& Ranney, 2010), results of such studies have limited generalizability.

Another strength of this study is that it utilizes a time-lagged design which alleviates concerns for common method variance (Podsakoff, MacKenzie, Lee, \& Podsakoff, 2003). According to Zapf, Dormann, and Frese (1996), self-report measures are especially susceptible to common method variance whereby the correlations between the independent and dependent variables are inflated. Hence, by utilizing a time-lagged design, this study provides confidence with regards to a causal influence of the five distinct safety-specific leaders behaviors, safety attitudes, safety norms, and perceived safety control on safety motivation (Vandenberg \& Scarpello, 1994).

This study also has several limitations that should be addressed. Despite the use of a time-lagged design and inclusion of control variables, the survey nature of this research makes it difficult to rule out all potential confounds and alternative explanations. Therefore, strong inferences of causality cannot be made even though the pattern of results is consistent with our hypothesized causal model (Singleton \& Straits, 1999). It is possible that additional third variables, such as safety climate and other personality traits (Christian et al., 2009) could have confounded the findings of this study. In addition to measuring and controlling for these variables, future research may consider utilizing a longitudinal study design with three or more waves.

The current study utilized a time-lagged design where the data for leadership behaviors and mediator variables were collected at Time 1, and safety motivation was assessed at Time 2 . According to Cole and Maxwell (2003), concurrent measurements between independent and mediating variables can lead to biased results. At the same time, safety motivation at Time 1 
could not be controlled due to the short time period of three months between assessments, and high stability of the measures across the two time points. Inclusion of highly stable variables in longitudinal research can be problematic as they overshadow the influence of independent variables (Cole, Martin, \& Steiger, 2005). Future research should attempt to replicate this study using three or more time points, as well as test a full panel design.

Another limitation of this study was the modest sample size. Study hypotheses were tested using 168 participants, which was substantially smaller sample than the needed sample size of 272 participants, as revealed by a priori power analysis. Recommendations for sample size in structural equation modeling (SEM) suggest obtaining a minimum of ten participants per indicator for adequate solutions (Bentler \& Chou, 1987). Since the sample size in this study did not meet this criterion, the entire model could not be tested simultaneously. In fact, an initial test of the full model which included all leadership variables did not provide acceptable fit to the data, and hence, could not be interpreted. To overcome the limitation of small sample size, a robust estimation method was used (Hu, Bentler, \& Kano, 1992). However, because the impact of all leadership variables on safety attitudes, norms, control, and motivation was tested separately, safety-specific leadership behaviors that were more salient could not be identified. For instance, results suggested that transformational and MEA, as well as MEP and laissez-faire leadership behaved similarly in predicting safety motivation. Future studies should attempt to test they hypothesized model in its entirety by using larger samples. 


\section{CHAPTER VI \\ CONCLUSIONS}

The goal of this study was to examine the role of full range of leader behaviors as specified by the Full-Range Leadership model (Bass, 1985), on safety motivation. In addition, using Theory of Planned Behavior (Ajzen, 1991) as a theoretical framework, this study further investigated attitudes, norms, and control toward safety behaviors as mechanisms in the safetyspecific leadership and safety motivation relationship using a time-lagged study design. Results indicated support for a relationship between positive leader behaviors (i.e., safety-specific transformational, contingent reward, and management-by-exception active) and safety motivation. In addition, safety attitudes mediated the relationship between safety-specific leader behaviors and safety motivation for transformational and management-by-exception active leadership. Safety norms acted as a mechanism in the leadership - safety motivation relationship for all five leadership behaviors. Safety control did not mediate the relationship between leadership and safety motivation for any of the leadership behaviors. The findings of this study expand our understanding of the different processes through which active and passive leader behaviors impact safety motivation, as well as provides avenues for leadership development. 


\section{REFERENCES}

Ajzen, I. (n.d.). Constructing a theory of planned behavior questionnaire. Retrieved from http://people.umass.edu/aizen/pdf/tpb.measurement.pdf

Ajzen, I. (1988). Attitudes, personality, and behavior. Chicago, IL: Dorsey Press.

Ajzen, I. (1991). The theory of planned behavior. Organizational Behavior and Human Decision Processes, 50(2), 179-211.

Ajzen, I., \& Fishbein, M. (1980). Understanding attitudes and predicting social behavior. Englewood Cliffs, NJ: Prentice-Hall.

Ajzen, I., \& Madden, T. J. (1986). Prediction of goal-directed behavior: Attitudes, intentions, and perceived behavioral control. Journal of Experimental Social Psychology, 22(5), 453474.

Andriessen, J. H. T. H. (1978). Safe behaviour and safety motivation. Journal of Occupational Accidents, 1(4), 363-376.

Antonakis, J., Avolio, B. J., \& Sivasubramaniam, N. (2003). Context and leadership: An examination of the nine-factor full-range leadership theory using the multifactor leadership questionnaire. The Leadership Quarterly, 14(3), 261-295.

Armitage, C. J., \& Conner, M. (2001). Efficacy of the theory of planned behavior: A meta-analytic review. British Journal of Social Psychology, 40(4), 471-499.

Atlantis, E., Chow, C. M., Kirby, A., \& Singh, M. A. (2006). Worksite intervention effects on physical health: A randomized controlled trial. Health Promotion International, 21(3), 191-200.

Avolio, B. J. (1999). Full leadership development: Building the vital forces in organizations. Thousand Oaks, CA: Sage Publications. 
Avolio, B. J., Bass, B. M., \& Jung, D. I. (1999). Re-examining the components of transformational and transactional leadership using the multifactor leadership questionnaire. Journal of Occupational and Organizational Psychology, 72, 441-462.

Barger, P., Behrend, T. S., Sharek, D. J., \& Sinar, E. F. (2011). IO and the crowd: Frequently asked questions about using Mechanical Turk for research. The Industrial-Organizational Psychologist, 49(2), 11-17.

Barling, J., Loughlin, C., \& Kelloway, E. K. (2002). Development and test of a model linking safety-specific transformational leadership and occupational safety. Journal of Applied Psychology, 87(3), 488-496.

Bass, B. M. (1985). Leadership and performance beyond expectations. New York, NY: The Free Press.

Bass, B. M. (1991). From transactional to transformational leadership: Learning to share the vision. Organizational Dynamics, 18(3), 19-31.

Bass, B. M. (1997). Does the transactional-transformational leadership paradigm transcend organizational and national boundaries? American Psychologist, 52(2), 130-139.

Bass, B. M. (1999). Two decades of research and development in transformational leadership. European Journal of Work and Organizational Psychology, 8(1), 9-32.

Bass, B. M., \& Avolio, B. J. (1997). The full range leadership development manual for the multifactor leadership questionnaire. Menlo Park, CA: Mind Garden.

Bass, B. M., Avolio, B. J., Jung, D. I., \& Berson, Y. (2003). Predicting unit performance by assessing transformational and transactional leadership. Journal of Applied Psychology, $88(2), 207-218$ 
Bass, B. M., \& Riggio, R. E. (2006). Transformational leadership. Mahwah, NJ: Lawrence Erlbaum Associates.

Batt, R., \& Valcour, P. M. (2003). Human resources practices as predictors of work-family outcomes and employee turnover. Industrial Relations: A Journal of Economy and Society, 42(2), 189-220.

Becker, T. E. (2005). Potential problems in the statistical control of variables in organizational research: A qualitative analysis with recommendations. Organizational Research Methods, 8(3), 274-289.

Bentler, P. M. (1990). Comparative fit indexes in structural models. Psychological Bulletin, 107(2), 238-246.

Bentler, P. M. (1995). EQS structural equations program manual. Encino, CA: Multivariate Software.

Bentler, P. M., \& Chou, C. P. (1987). Practical issues in structural modeling. Sociological Methods \& Research, 16(1), 78-117.

Bernhard, F., \& O’Driscoll, M. P. (2011). Psychological ownership in small family-owned businesses: Leadership style and nonfamily-employees' work attitudes and behaviors. Group \& Organization Management, 36(3), 345-384.

Biderman, M. D., \& Reddock, C. M. (2012). The relationship of scale reliability and validity to respondent inconsistency. Personality and Individual Differences, 52, 647-651.

Bommer, W. H., Rich, G. A., \& Rubin, R. S. (2005). Changing attitudes about change: Longitudinal effects of transformational leader behavior on employee cynicism about organizational change. Journal of Organizational Behavior, 26, 733-753. 
Boninger, D. S., Krosnick, J. A., \& Berent, M. K. (1995). Origins of attitude importance: Selfinterest, social identification, and value relevance. Journal of Personality and Social Psychology, 68(1), 61-80.

Bono, J. E., \& Anderson, M. H. (2005). The advice and influence networks of transformational leaders. Journal of Applied Psychology, 90(6), 1306-1314.

Boseman, G. (2008). Effective leadership in a changing world. Journal of Financial Service Professionals, 62(3), 36-38.

Breusch, T., \& Pagan, A. (1979). A simple test for heteroscedasticity and random coefficient variation. Econometrica, 47, 1287-1294.

Brosseau, L. M., \& Li, S. Y. (2005). Small business owners' health and safety intention: A crosssectional survey. Environmental Health: A Global Access Source, 4, $23-31$.

Browne, M. W., \& Cudeck, R. (1993). Alternative ways of assessing model fit. In K. A. Bollen \& J. S. Long (Eds.), Testing structural equation models (pp. 445-455). Newbury Park, CA: Sage.

Burke, M. J., Salvador, R. O., Smith-Crowe, K., Chan-Serafin, S., Smith, A., \& Sonesh, S. (2011). The dread factor: How hazards and safety training influence learning and performance. Journal of Applied Psychology, 96(1), 46-70.

Burke, M. J., Sarpy, S. A., Tesluk, P. E., \& Smith-Crowe, K. (2002). General safety performance: A test of a grounded theoretical model. Personnel Psychology, 55(2), 429457.

Burns, J. M. (1978). Leadership. New York, NY: Harper and Row.

Campbell, J. P. (1990). Modeling the performance prediction problem in industrial and 
organizational psychology. In M. D. Dunnette \& L. M. Hough (Eds.), Handbook of industrial and organizational psychology ( $2^{\text {nd }}$ ed., Vol. 1, pp. 687-732). Palo Alto, CA: Consulting Psychologists Press.

Casler, K., Bickel, L., \& Hackett, E. (2013). Separate but equal? A comparison of participants and data gathered via Amazon's Mturk, social media, and face-to-face behavioral testing. Computers in Human Behavior, 29(6), 2156-2160.

Cheung, G., \& Rensvold, R. (2002). Evaluating goodness-of-fit indexes for testing measurement invariance. Structural Equation Modeling, 9(2), 233-255.

Chiaburu, D. S., Diaz, I., \& Pitts, V. E. (2011). Social and economic exchanges with the organization: Do leader behaviors matter? Leadership \& Organization Development Journal, 32(5), 442-461.

Christian, M. S., Bradley, J. C., Wallace, J. C., \& Burke, M. J. (2009). Workplace safety: A meta-analysis of the roles of person and situation factors. Journal of Applied Psychology, 94(5), 1103-1127.

Clarke, S. (2006). The relationship between safety climate and safety performance: A metaanalytic review. Journal of Occupational Health Psychology, 11(4), 315-327.

Clarke, S. (2013). Safety leadership: A meta-analytic review of transformational and transactional leadership styles as antecedents of safety behaviours. Journal of Occupational and Organizational Psychology, 86, 22-49.

Clarke, S., \& Ward, K. (2006). The role of leader influence tactics and safety climate in engaging employees' safety participation. Risk Analysis, 26(5), 1175-1185.

Cleveland, W. S. (1979). Robust locally weighted regression and smoothing scatterplots. Journal of the American Statistical Association, 74(368), 829-836. 
Cohen, J., Cohen, P., West, S. G., \& Aiken, L. S. (2003). Applied multiple regression/correlation analysis for the behavioral sciences ( $3^{\text {rd }}$ ed.). Mahwah, NJ: Erlbaum.

Cole, D. A., Martin, N. C., \& Steiger, J. H. (2005). Empirical and conceptual problems with longitudinal trait-state models: Introducing a trait-state-occasion model. Psychological Methods, 10(1), 3.

Colémont, A., \& Van den Broucke, S. (2008). Measuring determinants of occupational health related behavior in Flemish farmers: An application of the theory of planned behavior. Journal of Safety Research, 39(1), 55-64.

Conchie, S. M. (2013). Transformational leadership, intrinsic motivation, and trust: A moderated-mediated model of workplace safety. Journal of Occupational Health Psychology, 18(2), 198-210.

Conchie, S. M., \& Donald, I. J. (2009). The moderating role of safety-specific trust on the relation between safety-specific leadership and safety citizenship behaviors. Journal of Occupational Health Psychology, 14(2), 137-147.

Dal Corso, L. (2008). Mediation effects of safety climate and safety motivation on the relation between organizational climate and safety performance in the workplace. Testing, Psychometrics, Methodology in Applied Psychology, 15(2), 77-90.

DeJoy, D. M., Schaffer, B. S., Wilson, M. G., Vandenberg, R. J., \& Butts, M. M. (2004). Creating safer workplaces: Assessing the determinants and role of safety climate. Journal of Safety Research, 35(1), 81-90.

Duffy, S. A., Ronis, D. L., Waltje, A. H., \& Choi, S. H. (2013). Protocol of a randomized controlled trial of sun protection interventions for operating engineers. BMC Public Health, 13(1), 273-279. 
Elenkov, D. S., Judge, W., \& Wright, P. (2005). Strategic leadership and executive innovation influence: An international multi-cluster comparative study. Strategic Management Journal, 26(7), 665-682.

Ellemers, N., De Gilder, D., \& Haslam, S. A. (2004). Motivating individuals and groups at work: A social identity perspective on leadership and group performance. Academy of Management Review, 29(3), 459-478.

Elliott, M. A., Armitage, C. J., \& Baughan, C. J. (2007). Using the theory of planned behaviour to predict observed driving behaviour. British Journal of Social Psychology, 46(1), 6990.

Epitropaki, O., \& Martin, R. (2005). The moderating role of individual differences in the relation between transformational/transactional leadership perceptions and organizational identification. The Leadership Quarterly, 16(4), 569-589.

Fan, X., Thompson, B., \& Wang, L. (1999). Effects of sample size, estimation methods, and model specification on structural equation modeling fit indexes. Structural Equation Modeling, 6(1), 56-83.

Fazio, R. H., \& Zanna, M. P. (1981). Direct experience and attitude-behavior consistency. In L. Berkowitz (Ed.), Advances in experimental social psychology (Vol.14, pp. 161-202). San Diego, CA: Academic Press.

Feldman, D. C. (1984). The development and enforcement of group norms. Academy of Management Review, 9(1), 47-53.

Fishbein, M. (2008). A reasoned action approach to health promotion. Medical Decision Making, 28(6), 834-844. 
Fishbein, M., \& Ajzen, I. (1975). Belief, attitude, intention and behavior: An introduction to theory and research. Reading, MA: Addison-Wesley.

Fogarty, G. J., \& Shaw, A. (2010). Safety climate and the theory of planned behavior: Towards the prediction of unsafe behavior. Accident Analysis and Prevention, 42(5), 1455-1459.

Ford, M. T., \& Tetrick, L. E. (2008). Safety motivation and human resource management in North America. The International Journal of Human Resource Management, 19(8), $1472-1485$.

Friedkin, N. E. (2001). Norm formation in social influence networks. Social Networks, 23(3), 167-189.

Fugas, C. S., Meliá, J. L., \& Silva, S. A. (2011). The "is" and "ought”: How do perceived social norms influence safety behaviors at work? Journal of Occupational Health Psychology, $16(1), 67-79$.

Fugas, C. S., Silva, S. A., \& Meliá, J. L. (2012). Another look at safety climate and safety behavior: Deepening the cognitive and social mediator mechanisms. Accident Analysis and Prevention, 45, 468-477.

Fugas, C. S., Silva, S. A., \& Meliá, J. L. (2013). Profiling safety behaviors: Exploration of the sociocognitive variables that best discriminate between different behavioral patterns. Risk Analysis, 33(5), 838-850.

Gardner, W. L., \& Avolio, B. J. (1998). The charismatic relationship: A dramaturgical perspective. Academy of Management Review, 23(1), 32-58.

Giles, M., \& Larmour, S. (2000). The theory of planned behavior: A conceptual framework to view the career development of women. Journal of Applied Social Psychology, 30(10), 2137-2157. 
Goldberg, L. R. (1992). The development of markers for the Big-Five factor structure. Psychological Assessment, 4(1), 26-42.

Goodman, J. K., Cryder, C. E., \& Cheema, A. (2013). Data collection in a flat world: The strengths and weaknesses of Mechanical Turk samples. Journal of Behavioral Decision Making, 26(3), 213-224.

Graham, J. W. (1988). Transformational leadership: Fostering follower autonomy, not automatic followership. Emerging Leadership Vistas, 73-79.

Gray, J. A. (1970). The psychophysiological basis of introversion-extraversion. Behaviour Research \& Therapy, 8(3), 249-266.

Greenberger, D. B., \& Strasser, S. (1986). Development and application of a model of personal control in organizations. Academy of Management Review, 11, 164-177.

Griffin, M. A., \& Hu, X. (2013). How leaders differentially motivate safety compliance and safety participation: The role of monitoring, inspiring, and learning. Safety Science, 60, 196-202.

Griffin, M. A., \& Neal, A. (2000). Perceptions of safety at work: A framework for linking safety climate to safety performance, knowledge, and motivation. Journal of Occupational Health Psychology, 5(3), 347-358.

Griffin, M. A., \& Talati, Z. (2014). Safety leadership. In D. Day (Ed.), The Oxford handbook of leadership and organizations. Oxford library of psychology (pp. 638-656). New York, NY: Oxford University Press.

Groves, K. S., \& LaRocca, M. A. (2011). An empirical study of leader ethical values, transformational and transactional leadership, and follower attitudes toward corporate social responsibility. Journal of Business Ethics, 103(4), 511-528. 
Hagger, M. S., \& Chatzisarantis, N. L. (2009). Integrating the theory of planned behavior and self-determination theory in health behavior: A meta-analysis. British Journal of Health Psychology, 14(2), 275-302.

Halbesleben, J. R., Leroy, H., Dierynck, B., Simons, T., Savage, G. T... \& Leon, M. R. (2013). Living up to safety values in health care: The effect of leader behavioral integrity on occupational safety. Journal of Occupational Health Psychology, 18(4), 395-405.

Haslam, S. A., Powell, C., \& Turner, J. (2000). Social identity, self-categorization, and work motivation: Rethinking the contribution of the group to positive and sustainable organisational outcomes. Applied Psychology, 49(3), 319-339.

Hinkin, T. R., \& Schriesheim, C. A. (2008). An examination of "nonleadership": From laissezfaire leadership to leader reward omission and punishment omission. Journal of Applied Psychology, 93(6), 1234-1248.

Hoffmeister, K., Gibbons, A. M., Johnson, S. K., Cigularov, K. P., Chen, P. Y., \& Rosecrance, J. C. (2014). The differential effects of transformational leadership facets on employee safety. Safety Science, 62, 68-78.

Hofmann, D. A., \& Jones, L. M. (2005). Leadership, collective personality, and performance. Journal of Applied Psychology, 90(3), 509-522.

Hofmann, D. A., \& Morgeson, F. P. (2004). The role of leadership in safety. In J. Barling \& M. Frone (Eds.), The psychology of workplace safety (pp. 159-180). Washington, DC: American Psychological Association.

Howell, J. M., \& Avolio, B. J. (1993). Transformational leadership, transactional leadership, locus of control, and support for innovation: Key predictors of consolidated-business-unit performance. Journal of Applied Psychology, 78(6), 891-902. 
Hu, L., \& Bentler, P. M. (1999). Cutoff criteria for fit indexes in covariance structure analysis: Convention criteria versus new alternatives. Structural Equation Modeling, 6(1), 1-55. Huang, Y. -H., Chen, P. Y., \& Grosch, J. W. (2010). Safety climate: New developments in conceptualization, theory, and research. Accident Analysis and Prevention, 42(5), 14211422.

Huang, Y. -H., Chen, P. Y., Krauss, A. D., \& Rogers, D. A. (2004). Quality of the execution of corporate safety policies and employee safety outcomes: Assessing the moderating role of supervisor safety support and the mediating role of employee safety control. Journal of Business and Psychology, 18(4), 483-506.

Huang, Y. H., Ho, M., Smith, G. S., \& Chen, P. Y. (2006). Safety climate and self-reported injury: Assessing the mediating role of employee safety control. Accident Analysis and Prevention, 38(3), 425-433.

IBM Corporation. (2011). IBM SPSS Statistics for Windows (Version 20.0). [Computer software]. Armonk, NY: Author.

Inness, M., Turner, N., Barling, J., \& Stride, C. B. (2010). Transformational leadership and employee safety performance: A within-person, between-jobs design. Journal of Occupational Health Psychology, 15(3), 279-290.

Isaac, R. G., Zerbe, W. J., \& Pitt, D. C. (2001). Leadership and motivation: The effective application of expectancy theory. Journal of Managerial Issues, 13(2), 212-226.

Ishikawa, J. (2012). Transformational leadership and gatekeeping leadership: The roles of norm for maintaining consensus and shared leadership in team performance. Asia Pacific Journal of Management, 29, 265-283. 
Ji, M., You, X., Lan, J., \& Yang, S. (2011). The impact of risk tolerance, risk perception and hazardous attitude on safety operation among airline pilots in China. Safety Science, 49(10), 1412-1420.

Jiang, L., \& Probst, T. M. (2016). Transformational and passive leadership as cross-level moderators of the relationships between safety knowledge, safety motivation, and safety participation. Journal of safety research, 57, 27-32.

Johnson, S. E., \& Hall, A. (2005). The prediction of safe lifting behavior: An application of the theory of planned behavior. Journal of Safety Research, 36(1), 63-73.

Jöreskog, K. G. (1969). A general approach to confirmatory maximum likelihood factor analysis. Psychometrika, 34(2), 183-202.

Joseph, C., Reddy, S., \& Sharma, K. K. (2013). Locus of control, safety attitudes and involvement in hazardous events in Indian army aviators. Aviation Psychology and Applied Human Factors, 3(1), 9-18.

Judge, T. A., \& Piccolo, R. F. (2004). Transformational and transactional leadership: A metaanalytic test of their relative validity. Journal of Applied Psychology, 89(5), 755-768.

Kapp, E. A. (2012). The influence of supervisor leadership practices and perceived group safety climate on employee safety performance. Safety Science, 50(4), 1119-1124.

Kark, R., \& Van Dijk, D. (2007). Motivation to lead, motivation to follow: The role of the selfregulatory focus in leadership processes. Academy of Management Review, 32(2), 500528.

Kath, L. M., Marks, K. M., \& Ranney, J. (2010). Safety climate dimensions, leader-member exchange, and organizational support as predictors of upward safety communication in a sample of rail industry workers. Safety Science, 48(5), 643-650. 
Kelloway, E. K , Francis, L., Schat, A. \& Iverson, R. (2005). Family socialization of young workers' safety attitudes. Paper presented at the annual meeting of the Society for Industrial/Organizational Psychology, Los Angeles, CA.

Kelloway, E. K., Mullen, J., \& Francis, L. (2006). Divergent effects of transformational and passive leadership on employee safety. Journal of Occupational Health Psychology, 11(1), 76-86.

Kelloway, E. K., Sivanathan, N., Francis, L., \& Barling, J. (2005). Poor leadership. Handbook of work stress, 89-112.

Keogh, J. P., Nuwayhid, I., Gordon, J. L., \& Gucer, P. (2000). The impact of occupational injury on injured worker and family: Outcomes of upper extremity cumulative trauma disorders in Maryland workers. American Journal of Industrial Medicine, 38(5), 498-506.

Kim, K. H. (2005). The relation among fit indexes, power, and sample size in structural equation modeling. Structural Equation Modeling: A Multidisciplinary Journal, 12(3), 368-390.

Landers, R. N., \& Behrend, T. S. (2015). An inconvenient truth: Arbitrary distinctions between organizational, Mechanical Turk, and other convenience samples. Industrial and Organizational Psychology, 8(02), 142-164.

Latham, G. P., \& Pinder, C. C. (2005). Work motivation theory and research at the dawn of the twenty-first century. Annual Review of Psychology., 56, 485-516.

Lee, D., Coustasse, A., \& Sikula, A., Sr. (2011). Transformational leadership and workplace injury and absenteeism: Analysis of a national nursing assistant survey. Health Care Management Review, 36(4), 380-387. 
Lee, J. -E., Almanza, B. A., Jang, S. S., Nelson, D. C., \& Ghiselli, R. F. (2013). Does transformational leadership style influence employees' attitudes toward food safety practices? International Journal of Hospitality Management, 33, 282-293.

Liberty Mutual Research Institute for Safety. (2012). Liberty Mutual workplace safety index. Hopkinton, MA.

Lievens, F., Van Geit, P., \& Coetsier, P. (1997). Identification of transformational leadership qualities: An examination of potential biases. European Journal of Work and Organizational Psychology, 6(4), 415-430.

Lin, H. F. (2010). Applicability of the extended theory of planned behavior in predicting job seeker intentions to use job-search websites. International Journal of Selection and Assessment, 18(1), 64-74.

Lingard, H. (2002). The effect of first aid training on Australian construction workers' occupational health and safety knowledge and motivation to avoid work-related injury or illness. Construction Management \& Economics, 20(3), 263-273.

Lo, M. -C., Ramayah, T., \& Min, H. W. (2009). Leadership styles and organizational commitment: A test on Malaysia manufacturing industry. African Journal of Marketing Management, 1(6), 133-139.

Locke, E. A. (1968). Toward a theory of task motivation and incentives. Organizational Behavior and Human Performance, 3(2), 157-189.

Locke, E. A., \& Latham, G. P. (2009). Has goal setting gone wild, or have its attackers abandoned good scholarship?. The Academy of Management Perspectives, 23(1), 17-23. 
Lowe, K. B., Kroeck, K. G., \& Sivasubramaniam, N. (1996). Effectiveness correlates of transformational and transactional leadership: A meta-analytic review of the MLQ literature. The Leadership Quarterly, 7(3), 385-425.

Lu, C. -S., \& Yang, C. -S. (2010). Safety leadership and safety behavior in container terminal operations. Safety Science, 48(2), 123-134.

MacKinnon, D. P., Lockwood, C. M., \& Williams, J. (2004). Confidence limits for the indirect effect: Distribution of the product and resampling methods. Multivariate Behavioral Research, 39(1), 99-128.

Mark, B. A., Hughes, L. C., Belyea, M., Chang, Y., Hofmann, D., Jones, C. B., \& Bacon, C. T. (2007). Does safety climate moderate the influence of staffing adequacy and work conditions on nurse injuries? Journal of Safety Research, 38(4), 431-446.

Martínez-Córcoles, M., Gracia, F. J., Tomás, I., Peiró, J. M., \& Schöbel, M. (2013). Empowering team leadership and safety performance in nuclear power plants: A multilevel approach. Safety Science, 51(1), 293-301.

Masi, R. J., \& Cooke, R. A. (2000). Effects of transformational leadership on subordinate motivation, empowering norms, and organizational productivity. The International Journal of Organizational Analysis, 8(1), 16-47.

Mayer, D. M., Kuenzi, M., Greenbaum, R., Bardes, M., \& Salvador, R. B. (2009). How low does ethical leadership flow? Test of a trickle-down model. Organizational Behavior and Human Decision Processes, 108(1), 1-13.

McCabe, B., Loughlin, C., Munteanu, R., Tucker, S., \& Lam, A. (2008). Individual safety and health outcomes in the construction industry. Canadian Journal of Civil Engineering, 35(12), 1455-1467. 
McColl-Kennedy, J. R., \& Anderson, R. D. (2005). Subordinate-manager gender combination and perceived leadership style influence on emotions, self-esteem and organizational commitment. Journal of Business Research, 58(2), 115-125.

Mester, C., Visser, D., Roodt, G., \& Kellerman, R. (2003). Leadership style and its relation to employee attitudes and behaviour. SA Journal of Industrial Psychology, 29(2), 77-82.

Michel, J. W., Wallace, D. L., \& Rawlings, R. A. (2013). Charismatic leaders: The role of admiration and system justification. Leadership and Organization Development Journal, $34(5), 469-487$.

Mullen, J. E., \& Kelloway, E. K. (2009). Safety leadership: A longitudinal study of the effects of transformational leadership on safety outcomes. Journal of Occupational and Organizational Psychology, 82(2), 253-272.

Mullen, J. E., \& Kelloway, E. K. (2011). Occupational health and safety leadership. In J. C. Quick \& L. E. Tetrick (Eds.), Handbook of occupational health psychology (2 ${ }^{\text {nd }}$ ed., pp. 357-372). Washington, DC: American Psychological Association.

Mullen, J., Kelloway, E. K., \& Teed, M. (2011). Inconsistent style of leadership as a predictor of safety behavior. Work \& Stress, 25(1), 41-54.

Muthén, L.K. and Muthén, B.O. (1998-2015). Mplus User’s Guide. Seventh Edition. Los Angeles, CA: Muthén \& Muthén.

Nahrgang, J. D., Morgeson, F. P., \& Hofmann, D. A. (2007). Predicting safety performance: A meta-analysis of safety and organizational constructs. Poster session presented at the 22nd annual conference of the society for industrial and organizational psychology, New York, NY. 
Nahrgang, J. D., Morgeson, F. P., \& Hofmann, D. A. (2011). Safety at work: A meta-analytic investigation of the link between job demands, job resources, burnout, engagement, and safety outcomes. Journal of Applied Psychology, 96(1), 71-94.

Neal, A. \& Griffin, M. A. (2004). Safety climate and safety at work. In J. Barling \& M. Frone (Eds.), The psychology of workplace safety (pp. 15-34). Washington, DC: American Psychological Association.

Neal, A., \& Griffin, M. A. (2006). A study of the lagged relationships among safety climate, safety motivation, safety behavior, and accidents at the individual and group levels. Journal of Applied Psychology, 91(4), 946-953.

Neal, A., Griffin, M. A., \& Hart, P. M. (2000). The impact of organizational climate on safety climate and individual behavior. Safety Science, 34(1), 99-109.

Nevitt, J., \& Hancock, G. R. (2001). Performance of bootstrapping approaches to model test statistics and parameter standard error estimation in structural equation modeling. Structural Equation Modeling, 8(3), 353-377.

Norman, P., Conner, M., \& Bell, R. (2000). The theory of planned behaviour and exercise: Evidence for the moderating role of past behaviour. British Journal of Health Psychology, 5(3), 249-261.

Northouse, P. G. (2012). Leadership: Theory and practice $\left(6^{\text {th }}\right.$ ed.). Thousand Oaks, CA: Sage.

Nielsen, M. B. (2013). Bullying in work groups: The impact of leadership. Scandinavian journal of psychology, 54(2), 127-136.

Nunnally, J. C., \& Bernstein, I. H. (1994). Psychometric theory ( $3^{\text {rd }}$ ed.). New York, NY: McGraw-Hill. 
Othman, A., \& Wanlabeh, N. (2012). Teachers' perspectives on leadership practices and motivation in Islamic private schools, Southern Thailand. Asian Education and Development Studies, 1(3), 237-250.

Parker, S. K., Axtell, C. M., \& Turner, N. (2001). Designing a safer workplace: Importance of job autonomy, communication quality, and supportive supervisors. Journal of Occupational Health Psychology, 6(3), 211-228.

Parker, S. K., \& Griffin, M. A. (2002). What is so bad about a little name-calling? Negative consequences of gender harassment for overperformance demands and distress. Journal of Occupational Health Psychology, 7(3), 195.

Paolacci, G., \& Chandler, J. (2014). Inside the Turk: Understanding Mechanical Turk as a participant pool. Current Directions in Psychological Science, 23(3), 184-188.

Paolacci, G., Chandler, J., \& Ipeirotis, P. G. (2010). Running experiments of Amazon Mechanical Turk. Judgment and Decision Making, 5, 411-419.

Petraitis, P. S., Dunham, A. E., \& Niewiarowski, P. H. (1996). Inferring multiple causality: The limitations of path analysis. Functional Ecology, 421-431.

Pierce, J. L., Kostova, T., \& Dirks, K. T. (2001). Toward a theory of psychological ownership in organizations. Academy of Management Review, 26(2), 298-310.

Pihie, Z. A. L., Sadeghi, A., \& Elias, H. (2011). Analysis of head of departments leadership styles: Implication for improving research university management practices. ProcediaSocial and Behavioral Sciences, 29, 1081-1090.

Pinder, C. C. (1998). Work motivation in organizational behavior. Upper Saddle River, NJ: Prentice-Hall. 
Podsakoff, P. M., Bommer, W. H., Podsakoff, N. P., \& MacKenzie, S. B. (2006). Relationships between leader reward and punishment behavior and subordinate attitudes, perceptions, and behaviors: A meta-analytic review of existing and new research. Organizational Behavior and Human Decision Processes, 99, 113-142.

Podsakoff, P. M., MacKenzie, S. B., Lee, J. Y., \& Podsakoff, N. P. (2003). Common method biases in behavioral research: A critical review of the literature and recommended remedies. Journal of Applied Psychology, 88(5), 879.

Podsakoff, P. M., MacKenzie, S. B., Moorman, R. H., \& Fetter, R. (1990). Transformational leader behaviors and their effects on followers' trust in leader, satisfaction, and organizational citizenship behaviors. The Leadership Quarterly, 1(2), 107-142.

Preacher, K. J., \& Hayes, A. F. (2008). Asymptotic and resampling strategies for assessing and comparing indirect effects in multiple mediator models. Behavior Research Methods, 40(3), 879-891.

Rabey, G. P. (2001). Motivation is response. Industrial and Commercial Training, 33(1), 26-28.

Ryan, A. M., Chan, D., Ployhart, R. E., \& Slade, L. A. (1999). Employee attitude surveys in a multinational organization: Considering language and culture when assessing measurement equivalence. Personnel Psychology, 52, 37-58.

Ryan, J. C., \& Tipu, S. A. (2013). Leadership effects on innovation propensity: A two-factor full range leadership model. Journal of Business Research, 66(10), 2116-2129.

Salancik, G. R., \& Pfeffer, J. (1978). A social information processing approach to job attitudes and task design. Administrative Science Quarterly, 224-253. 
Sawhney, G., \& Cigularov, K. P. (2014). Measurement equivalence and latent mean differences of personality scores across different media and proctoring administration conditions. Computers in Human Behavior, 36, 412-421.

Shamir, B. (1991). Meaning, self and motivation in organizations. Organization Studies, 12(3), 405-424.

Shamir, B., House, R. J., \& Arthur, M. B. (1993). The motivational effects of charismatic leadership: A self-concept based theory. Organization Science,4(4), 577-594.

Shamir, B., Zakay, E., Breinin, E., \& Popper, M. (1998). Correlates of charismatic leader behavior in military units: Subordinates' attitudes, unit characteristics, and superiors' appraisals of leader performance. Academy of Management Journal, 41(4), 387-409.

Shrout, P. E., \& Bolger, N. (2002). Mediation in experimental and nonexperimental studies: New procedures and recommendations. Psychological Methods, 7(4), 422-445.

Sims , H. P. Jr., \& Szilagyi, A. D. (1979). Time lags in leader reward research. Journal of Applied Psychology, 64(1), 66-71.

Singleton, R., \& Straits, B. C. (1999). Approaches to social research (3 ${ }^{\text {rd }}$ ed.). New York, NY: Oxford Press.

Smith, N. A., Sabat, I. E., Martinez, L. R., Weaver, K., \& Xu, S. (2015). A convenient solution: Using MTurk to sample from hard-to-reach populations. Industrial and Organizational Psychology, 8(2), 220-228.

Smith-Crowe, K., Burke, M. J., \& Landis, R. S. (2003). Organizational climate as a moderator of safety knowledge-safety performance relationships. Journal of Organizational Behavior, $24(7), 861-876$ 
Snyder, L. A., Krauss, A. D., Chen, P. Y., Finlinson, S., \& Huang, Y. -H. (2011). Safety performance: The mediating role of safety control. Work: A Journal of Prevention, Assessment and Rehabilitation, 40(1), 99-111.

Steiger, J. H. (1990). Structural model evaluation and modification: An interval estimation approach. Multivariate Behavioral Research, 25(2), 173-180.

Tabachnick, B. G., \& Fidell, L. S. (2013). Using multivariate statistics. Boston, MA: Pearson Education.

Taggar, S., \& Ellis, R. (2007). The role of leaders in shaping formal team norms. The Leadership Quarterly, 18(2), 105-120.

Terry, D. J., \& Hogg, M. A. (1996). Group norms and the attitude-behavior relationship: A role for group identification. Personality and Social Psychology Bulletin, 22(8), 776-793.

Tesluk, P., \& Quigley, N. R. (2003). Group and normative influences on health and safety perspectives from taking a broad view on team effectiveness. In D. A. Hoffman \& L. E. Tetrick (Eds.), Health and Safety in Organizations: A Multilevel Perspective (pp. 131172). San Francisco, CA: Jossey-Bass.

Thompson, C. A., \& Prottas, D. J. (2005). Relationships among organizational family support, job autonomy, perceived control, and employee well-being. Journal of Occupational Health Psychology, 11(1), 100-118.

Timo Gnambs (n.d). Required sample size and power for SEM. Retrieved from http://timo.gnambs.at/en/scripts/powerforsem

Törner, M., \& Pousette, A. (2009). Safety in construction-a comprehensive description of the characteristics of high safety standards in construction work, from the combined 
perspective of supervisors and experienced workers. Journal of Safety Research, 40(6), 399-409.

Tucker, S., Chmiel, N., Turner, N., Hershcovis, M. S., \& Stride, C. B. (2008). Perceived organizational support for safety and employee safety voice: The mediating role of coworker support for safety. Journal of Occupational Health Psychology, 13(4), 319-330.

U.S. Bureau of Labor Statistics. (2013a). National census of fatal occupational injuries in 2013. Retrieved from http://www.bls.gov/news.release/pdf/cfoi.pdf

U.S. Bureau of Labor Statistics. (2013b). Nonfatal occupational injuries and illnesses requiring days away from work, 2012. Retrieved from http://stats.bls.gov/news.release/archives/osh2 11262013.pdf

U.S. Department of Labor (n.d.). Costs of accidents. Retrieved from https://www.osha.gov/SLTC/etools/safetyhealth/mod1 costs.html

Van Breukelen, W., Van der Vlist, R., \& Steensma, H. (2004). Voluntary employee turnover: Combining variables from the 'traditional' turnover literature with the theory of planned behavior. Journal of Organizational Behavior, 25(7), 893-914.

Vandenberg, R. J., \& Scarpello, V. (1994). A longitudinal assessment of the determinant relationship between employee commitments to the occupation and the organization. Journal of Organizational Behavior, 15(6), 535-547.

Vandenberghe, C., Stordeur, S., \& D'hoore, W. (2002). Transactional and transformational leadership in nursing: Structural validity and substantive relationships. European Journal of Psychological Assessment, 18(1), 16-29. 
Vinodkumar, M. N., \& Bhasi, M. (2010). Safety management practices and safety behaviour: Assessing the mediating role of safety knowledge and motivation. Accident Analysis \& Prevention, 42(6), 2082-2093.

Vroom, V. H. (1964). Work and motivation. New York, NY: Wiley.

Walumbwa, F. O., Hartnell, C. A., \& Oke, A. (2010). Servant leadership, procedural justice climate, service climate, employee attitudes, and organizational citizenship behavior: A cross-level investigation. Journal of Applied Psychology, 95(3), 517-529.

Wang, G., Oh, I. -S, Courtright, S. H., \& Colbert, A. E. (2011). Transformational leadership and performance across criteria and levels: A meta-analytic review of 25 years of research. Group \& Organization Management, 36(2), 223-270.

Wills, A., Watson, B., \& Biggs, H. (2009). An exploratory investigation into safety climate and work-related driving. Work: A Journal of Prevention, Assessment and Rehabilitation, 32(1), 81-94.

Yoon, J., Han, N. -C., \& Seo, Y. -J. (1996). Sense of control among hospital employees: An assessment of choice process, empowerment, and buffering hypotheses. Journal of Applied Social Psychology, 26(8), 686-716.

Zacharatos, A., Barling, J., \& Iverson, R. D. (2005). High-performance work systems and occupational safety. Journal of Applied Psychology, 90(1), 77-93.

Zapf, D., Dormann, C., \& Frese, M. (1996). Longitudinal studies in organizational stress research: A review of the literature with reference to methodological issues. Journal of Occupational Health Psychology, 1(2), 145-169.

Zhu, W., Sosik, J. J., Riggio, R. E., \& Yang, B. (2012). Relationships between transformational and active transactional leadership and followers' organizational identification: The role 
of psychological empowerment. Journal of Behavioral and Applied Management, 13(3), $186-212$

Zohar, D. (2000). A group-level model of safety climate: Testing the effect of group climate on microaccidents in manufacturing jobs. Journal of Applied Psychology, 85(4), 587-596.

Zohar, D. (2002a). Modifying supervisory practices to improve subunit safety: A leadershipbased intervention model. Journal of Applied Psychology, 87(1), 156-163.

Zohar, D. (2002b). The effects of leadership dimensions, safety climate, and assigned priorities on minor injuries in work groups. Journal of Organizational Behavior, 23(1), 75-92.

Zohar, D. (2011). Safety climate: Conceptual and measurement issues. In J. Quick \& L. Tetrick (Eds.), Handbook of occupational health psychology $2^{\text {nd }}$ Edition (pp. 141-164). Washington, DC: American Psychological Association.

Zohar, D., \& Luria, G. (2003). The use of supervisory practices as leverage to improve safety behavior: A cross-level intervention model. Journal of Safety Research, 34(5), 567-577.

Zohar, D., \& Polachek, T. (2014). Discourse-based intervention for modifying supervisory communication as leverage for safety climate and performance improvement: A randomized field study. Journal of Applied Psychology, 99(1), 113-124. 


\section{APPENDIX A \\ DEMOGRAPHIC SURVEY}

Please complete this one-minute demographic survey if you work in an occupation where safety is of concern:

1. Are you currently employed?

2. On average, how many hours do you work per week?

3 . What is the primary industry of your organization?

4. What is your current position?

5. How long have you been working at your current job?

6. How long have you been working with your current direct supervisor?

7. How long have you been working for your current employer?

8. What is your year of birth?

9. What is your gender?

10 . What is your racial or ethnic group? 


\section{APPENDIX B}

\section{SYNTAX FOR POWER ANALYSIS}

$\underline{\text { Syntax for Comparative Fit Index }}$

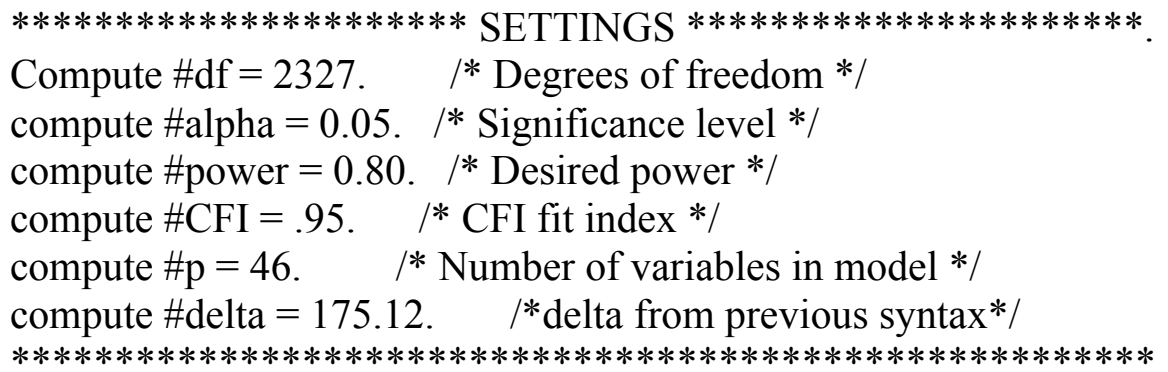

Compute \#nCFI $=(\#$ delta $+\#$ df* $(1-\# C F I)) /(21.533259 *(1-\# C F I))+1$.

Print /'Required N for CFI fit index (Kim, 2005):' \#nCFI.

Exe.

$\underline{\text { Syntax for Root Mean Square Error of Approximation }}$

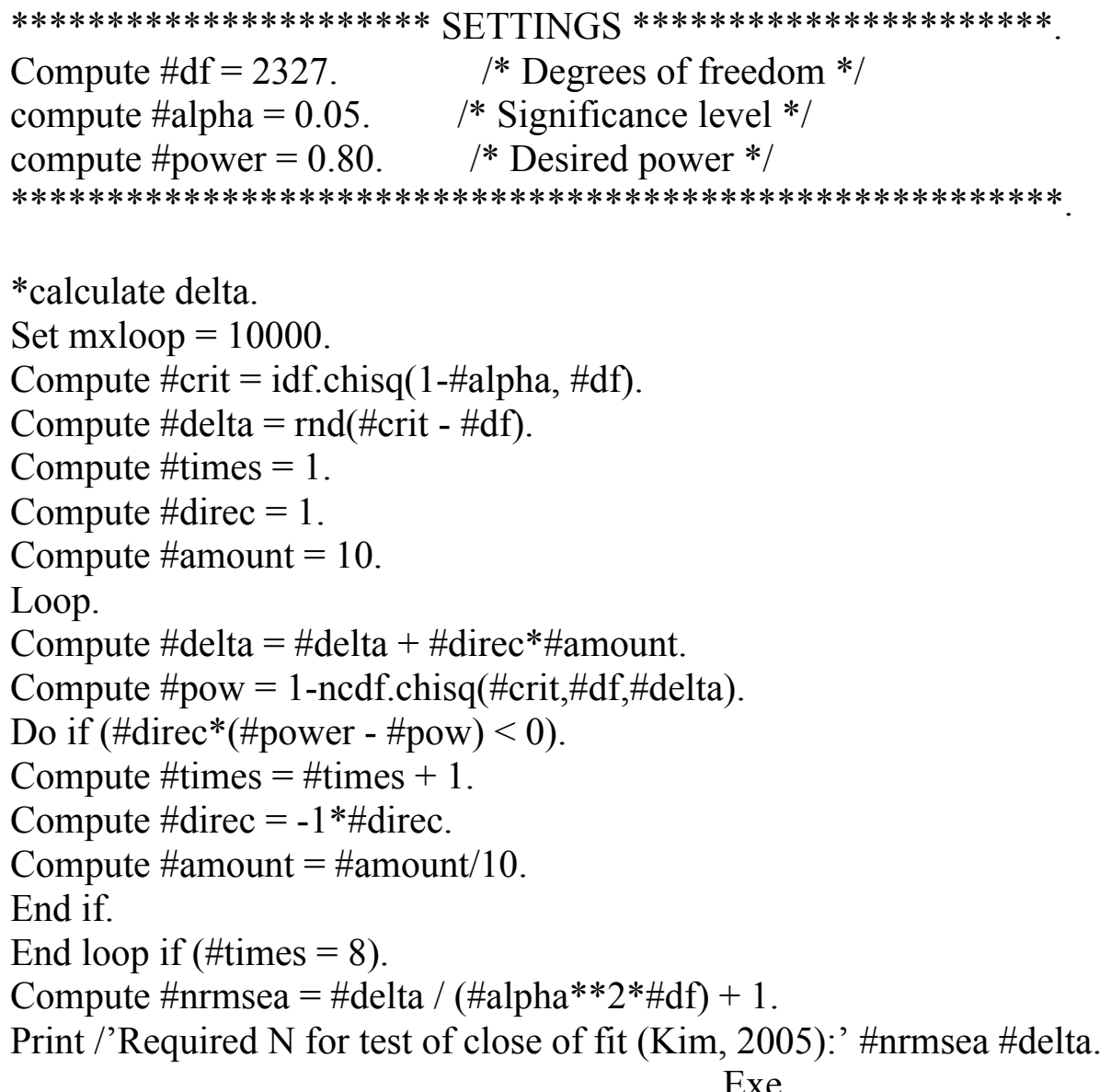

Exe. 


\section{APPENDIX C \\ STUDY MEASURES}

\section{Safety-specific leadership}

Rating scale: $1=$ Not at all, $2=$ Once in a While, $3=$ Sometimes, $4=$ Fairly Often, $5=$ Frequently or Always

Please answer the following questions regarding your current, immediate supervisor at work:

\section{Transformational Leadership}

1. My supervisor provides continuous encouragement to do our jobs safely

2. My supervisor shows determination to maintain a safe work environment

3. My supervisor suggests new ways of doing our jobs more safely

4. My supervisor encourages me to express my ideas and opinions about safety at work

5. My supervisor talks about his values and beliefs of the importance of safety

6. My supervisor behaves in a way that displays commitment to a safe workplace

7. My supervisor spends time showing me the safest way to do things at work

8. My supervisor would listen to my concerns about safety on the job

\section{Contingent Reward}

1. My supervisor makes clear what one can expect to receive when safety goals are achieved

2. My supervisor expresses satisfaction when I meet safety expectations

3. Gives me recognition when my work is completed safely

4. My supervisor makes sure that we receive appropriate rewards for achieving safety targets on the job

\section{Management-by-Exception Active}

1. My supervisor keeps track of all safety mistakes

2. My supervisor concentrates his/her full attention on dealing with safety- mistakes, complaints, and failures

3. My supervisor directs my attention toward failures to meet safety standards

4. My supervisor focuses attention on irregularities, exceptions, and deviations from safety standards

\section{Management-by-Exception Passive}

1. My supervisor waits for things to go wrong before taking action

2. My supervisor fails to intervene until safety problems become serious

\section{Laissez-Faire}

1. My supervisor avoids making decisions that affect safety on the job

2. My supervisor is absent when safety issues arise

3. My supervisor avoids any involvement in safety matters on the job 
4. My supervisor delays responding to safety questions or requests for assistance with safety issues

Attitudes toward safety behaviors

Rating Scale: $1=$ Strongly Disagree to $7=$ Strongly Agree

1. For me, it is more important to work safely than it is to work quickly

2. For me, getting the job done is not as important as working safely

3. For me, it is important to work safely even if it takes longer to do the work

4. For me, it is important to work safely even if it is inconvenient

Norms for Engaging in Safety Behavior

Rating Scale: $1=$ Strongly Disagree to $7=$ Strongly Agree

Injunctive norms

1. Most co-workers whose opinions I value approve of my using necessary safety equipment to do my job

2. Most co-workers whose opinions I value approve of my using the correct safety procedures for carrying out my job

3. Most co-workers whose opinions I value encourage me to voluntarily carry out tasks or activities to improve workplace safety

\section{Descriptive Norms}

1. Most co-workers whose opinions I value use the necessary safety equipment regularly

2. Most co-workers whose opinions I value promote safety within the workplace

3. Most co-workers whose opinions I value pursue the highest safety standards when carrying out their jobs

Perceived Control over Safety Behavior

Rating Scale: $1=$ Strongly Disagree to $7=$ Strongly Agree

1. I am able to change unsafe practices at work

2. I am capable of taking action to prevent injuries or accidents to myself at work

3. I am able to change the unsafe behavior of others at work

4. My job allows me to control whether I am safe at work

Motivation to Perform Safety Behaviors

Rating Scale: $1=$ Strongly Disagree to $7=$ Strongly Agree

1. Even when I am running behind schedule, I intend to follow safety policies

2. I am motivated to think of new ways of making my workplace a safer environment

3. I intend to follow all safety procedures even when I have deadlines to meet 
4. I am willing to comply with safety rules even when I am not asked to do so

5. I plan to attend safety meetings even if they are not mandatory

6. I will make an effort to work safely even when others around me work in an unsafe manner

Control variables

Demographic variables

1. What is your age?

2. What is your gender (Male, Female)

3. What is your ethnicity (African American, Asian/Pacific Islander, Caucasian, Hispanic, Multiracial, Native American, Other, Not Sure, Not applicable)

4. On average, how many hours do you work per week?

5. What is your current position?

6. How long have your been working at your current job?

7. How long have you been working with your current supervisor?

8. How long have you been working at the current organization?

\section{Conscientiousness}

Rating Scale: $1=$ Very Inaccurate to 5=Very Accurate

1) I am always prepared.

2) I leave my belongings around.

3) I pay attention to details.

4) I make a mess of things.

5) I get chores done right away.

6) I often forget to put things back in their proper place.

7) I like order.

8) I shirk my duties.

9) I follow a schedule.

10) I am exacting in my work.

\section{Safety training}

1. How many hours of safety training have you completed in the last 6 months?

2. Have you completed OSHA 10 and/or OSHA 30 certification? 


\title{
VITA
}

\author{
Gargi Sawhney \\ Department of Psychology \\ Old Dominion University \\ Norfolk, VA 23529
}

\section{Education}

Old Dominion University, Norfolk, VA; Ph.D. in Industrial/Organizational Psychology, Expected Aug., 2016

Illinois Institute of Technology, Chicago, IL; M.S. in Industrial/Organizational Psychology, May, 2011

Northeastern Illinois University, Chicago, IL; B.A. in Psychology, Aug., 2008

University of Delhi, India; B.A. in English Honors, Aug., 2005

\section{Professional Work Experience}

Post Doctoral Fellow, Clemson University, March 2016 - Present

Research Analyst, AbbVie, May 2015 - Dec. 2015

Graduate Research Assistant, Old Dominion University, Aug. 2010 - May 2013

Organizational Development Intern, Advocate Health Care, May 2010 - Aug. 2010

Graduate Assistant, Illinois Institute of Technology, Aug. 2009 - May 2010

Associate Consultant, Center for Research and Service, Feb. 2009 - May 2010

\section{Select Publications and Presentations}

Sawhney, G., \& Cigularov, K. P. (2014). Measurement equivalence and latent mean differences of personality scores across different media and proctoring administration conditions. Computers in Human Behavior, 36, 412-421.

Sawhney, G., \& Cigularov, K. P. (2015, May). Examining safety attitudes, norms, and control as mediators of leadership effects on employee safety motivation. In G. Sawhney \& K. P. Cigularov (Cochairs), Examining the role of safety-specific leadership in the workplace. Symposium presented at the Work, Stress, and Health Conference, Atlanta, GA.

Sawhney, G. (2015, May). Chair, Safety efficacy, climate and attitudes. Symposium conducted at the Work, Stress, and Health Conference, Atlanta, GA.

Sawhney, G., \& Cigularov, K. P. (2014, May). Examining measurement equivalence of the Big Five personality inventory. In G. Sawhney \& K. P. Cigularov (Co-chairs), Measurement equivalence of personality measures across different methods and cultures. Symposium paper presented at the $29^{\text {th }}$ Annual Conference of the Society for Industrial and Organizational Psychology, Honolulu, HI.

Sawhney, G. (2013, May). Chair, Investigating workplace hazards, conflicts, and personality: Promoting injury reporting and risk communication. Symposium conducted at the $10^{\text {th }}$ International Conference on Occupational Stress and Health, Los Angeles, California.

Sawhney, G., Cigularov, K. P., \& Kines, P. (2013, May). Measurement equivalence and latent mean differences of safety climate measures across industries, positions, and gender. Symposium paper presented at the $10^{\text {th }}$ International Conference on Occupational Stress and Health, Los Angeles, California. 